\title{
IMPLEMENTASI TOPOLOGI HYBRID UNTUK PENGOPTIMALAN APLIKASI EDMS PADA PROJECT OFFICE PT PHE ONWJ
}

\author{
Charles Widodo, Marchellius Yana, Halim Agung \\ Teknik Informatika Universitas Bunda Mulia DKI Jakarta \\ charwidodo@gmail.com, marchellgabriel@gmail.com, hagung@bundamulia.ac.id
}

\begin{abstract}
ABSTRAK
Penggunaan aplikasi EDMS di project office PT PHE ONWJ dinilai masih belum optimal karena masih lambat dalam pengunaan aplikasi EDMS. Oleh karena itu dilakukanlah penelitian ini dengan tujuan untuk mengoptimalkan jaringan yang digunakan untuk mengakses aplikasi EDMS pada project office PT PHE ONWJ. Pengoptimalan jaringan yang dimaksud adalah dengan membangun topologi di project office PT PHE ONWJ dan menerapkan metro sebagai perantara topologi star di project office dan topologi star dikantor pusat sehingga menciptakan topologi hybrid. Topologi hybrid yang dimaksud adalah penggabungan antara topologi star yang ada di jaringan pusat, metro sebagai perantara kantor pusat dengan project office PT PHE ONWJ dan topologi star yang akan dibangun di project office PT ONWJ. Diharapkan setelah menerapkan topologi yang telah dirancang dapat mengoptimalkan penggunaan aplikasi EDMS. Topologi star di project office PT ONWJ dan metro sebagai perantara 2 topologi kantor pusat dan project office menghasilkan topologi hybrid. Kesimpulan dari penelitian ini adalah penerapan topologi dalam jaringan dapat memberikan optimalisasi dibandingkan dengan tanpa menerapkan topologi. Hasil rata-rata ping saat pengaksesan aplikasi EDMS sebelum menerapkan topologi hybrid mendapatkan hasil sebesar 392,98 ms dan setelah menerapkan topologi hybrid mendapatkan hasil sebesar 143,50 ms, sehingga disimpulkan bahwa penerapan topologi hybrid lebih baik dalam menjalankan aplikasi EDMS.
\end{abstract}

Kata Kunci: EDMS, Topologi, Metro, Hybrid, Pengoptimalan

\begin{abstract}
The use of EDMS application in PT PHE ONWJ project office is considered not optimal because it is still slow in the use of EDMS applications. Therefore this study was conducted with the aim to optimize the network used to access the EDMS application on the PT PHE ONWJ project office. Network optimization in question is to build a topology in the project office of PT PHE ONWJ and apply the metro as an intermediate star topology in the project office and star topology at the headquarters so as to create a hybrid topology. Hybrid topology in question is a merger between the star topology in the central network, metro as an intermediary head office with PT PHE ONWJ project office and star topology to be built at PT ONWJ project office. It is expected that after applying the topology that has been designed to optimize the use of EDMS applications. Star topology in PT ONWJ project office and metro as intermediary 2 topology headquarters and project office produce hybrid topology. The conclusion of this research is application of topology in network can give optimization compared with without applying topology. The average result of ping when accessing EDMS application before applying hybrid topology got $392.98 \mathrm{~ms}$ result and after applying hybrid topology get result of $143,50 \mathrm{~ms}$, so it is concluded that application of hybrid topology is better in running EDMS application.
\end{abstract}

Keywords: EDMS, Topology, Metro, Hyrbid, Optimization

DOI : $10.15408 /$ jti.v11i1.6472 


\section{PENDAHULUAN}

Bagi PT PHE ONWJ, kegiatan dokumentasi merupakan asset paling penting untuk menunjang kebutuhan informasi berharga bagi berbagai pihak tiap organisasi dan departemen. Dalam hal ini kecepatan akses pencarian, kemudahan dan keamanan penyimpanan, serta dapat menjamin bahwa dokumen tersebut selalu perbaharui dan tidak rusak. Maka diperlukan penerapan Electronic Document Management System (EDMS) guna penyimpanan dan pengindeksan dokumen, untuk mencari dan penarikan yang mudah, integrasi dengan paket software perkantoran dan sistem pengiriman pesan, memungkinkan kerja kolaborasi, dan menyediakan kontrol akses dari dokumen. Dikarenakannya jaringan EDMS pada project office PT PHE ONWJ dinilai kurang optimal pengoperasiannya, maka penelitian ini membuat perancangan pengoptimalan kecepatan pengaksesan aplikasi EDMS pada PT PHE ONWJ dengan menggunakan topologi Hybrid.

Penelitian terdahulu membahas tentang Analisis Simulasi Topologi Hybrid Pada Wireless Sensor Network Menggunakan Protokol Routing Optimized Link State Routing Dan Dynamic Source Routing. Kemudian dalam penelitian dengan analisis WSN topologi hybrid pada routing protocol DSR dan OLSR menggunakan standard IEEE 802.15.4, bahwa routing protocol DSR lebih baik dalam hal pengaplikasiannya [1].

Penelitian terdahulu kedua membahas tentang Analisis Perbandingan Kinerja Topologi MESH dan HYBRID Pada Jaringan Optik WDM Dengan Menggunakan Algoritma First-Fit. Kemudian dalam penelitian dengan input parameter yang sama terhadap topologi Mesh dan Hybrid, Mesh menunjukkan kinerja yang lebih baik dengan adanya nilai tertinggi yang dicapai oleh Mesh yang memiliki selisih perbedaan nilai dengan Hybrid. Artinya bahwa dalam suatu jaringan yang memiliki link lebih banyak dengan panjang gelombang yang sama akan menghasilkan kinerja yang lebih baik. [2].

Penelitian terdahulu ketiga membahas tentang Sistem Pendeteksian Penyusupan Jaringan Komputer Dengan Active Response Menggunakan Metode Hybrid Intrusion Detection, Signatures dan Anomaly Detection. Kemudian dalam penelitian Hybrid Intrusion Detection Management System (HyDManSys) dapat melakukan capture, analisa dan respon (blocking access) pada penyusupan jaringan sehingga berperan aktif dalam pendeteksian, dengan mengintegrasikan metode Hybrid Instrusion Detection System, Signatures dan Anomaly Detection [3].

Penulis memilih topologi Hybrid berdasarkan referensi jurnal pendahulu tentang pembahasan Analisis Simulasi Topologi Hybrid Pada Wireless Sensor Network Menggunakan Protokol Routing Optimized Link State Routing Dan Dynamic Source Routing, Analisis Perbandingan Kinerja Topologi MESH dan HYBRID Pada Jaringan Optik WDM Dengan Menggunakan Algoritma First-Fit, dan Sistem Pendeteksian Penyusupan Jaringan Komputer Dengan Active Response Menggunakan Metode Hybrid Instrusion Detection Management System (HyDManSys) yang berperan aktif dalam pendeteksian.

\section{KAJIAN LITERATUR}

\subsection{Jaringan Komputer}

Jaringan Komputer adalah sekelompok komputer otonom yang saling berhubungan satu sama lainnnya menggunakan protokol komunikasi melalui media komunikasi sehingga dapat saling berbagi informasi, aplikasi, dan perangkat keras secara bersamasama [4].

\subsection{Local Area Network}

Local Area Network (LAN) digunakan untuk menghubungkan komputer-komputer pribadi dan workstation dalam suatu perusahaan yang menggunakan peralatan secara bersama-sama dan saling bertukar informasi [4].

\subsection{Topologi Jaringan}

Topologi jaringan adalah salah satu aturan bagaimana menghubungkan komputer (node) satu sama lain secara fisik dan pola hubungan antara komponen-komponen yang berkomunikasi melalui media atau peralatan jaringan, seperti server, workstation, hub/switch, dan pemasangan kabel (media transmisi data) [5].

\subsection{Metropolitan Area Network (MAN)}

Merupakan versi LAN yang mempunyai ukuran lebih besar. MAN merupakan alternatif pembuatan jaringan computer antar kantor 
dalam suatu kota. Jangkauan MAN antara 10 sampai dengan 50 kilometer [4].

\subsection{Wide Area Network (WAN)}

Wide Area Network adalah jaringan yang memiliki jarak sangat jauh, karena radiusnya mencakup sebuah Negara atau bahkan benua. WAN terhubung melalui saluran telekomunikasi dan berinteraksi dengan jaringan lain menggunakan media yang disebut router [4].

\subsection{Router}

Pengertian router adalah peralatan jaringan yang dapat menghubungkan satu jaringan dengan jaringan lain. Router bekerja menggunakan routing table yang disimpan di memory-nya untuk membuat keputusan tentang kemana dan bagaimana paket dikirimkan. Router merupakan perangkat yang dikhususkan untuk menangani koneksi antara dua atau lebih jaringan yang terhubung melalui packet switching.

Router bekerja dengan melihat alamat asal dan alamat tujuan dari paket yang melewatinya dan memutuskan rute yang akan dilewati paket tersebut untuk sampai ketujuan

\subsection{Mikrotik}

Mikrotik merupakan system operasi linux base yang diperuntukkan sebagai network router. Didesain untuk memberikan kemudahan bagi penggunanya. Administrasinya bisa dilaukan melalui windows application (winbox). Selain itu instalasi dapat dilakukan pada standard komputer PC (Personal Computer). PC yang akan dijadikan router mikrotik tidak memerlukan resource yang cukup besar untuk penggunaan standard, misalnya hanya sebagai gateway [6].

\subsection{Virtual Private Network (VPN)}

Sebuah teknologi jaringan komputer yang dikembangkan oleh perusahaan skala besar yang menghubungkan antar jaringan diatas jaringan lain menggunakan intranet yang membutuhkan jalur privacy dan komunikasinya [7].

\subsection{Firewall}

Merupakan suatu cara atau mekanisme yang ditetapkan baik terhadap hardware, software, ataupun sistem dengan tujuan untuk melindungi. Perlindungan dapat dilakukan dengan menyaring, membatasi, atau bahkan menolak suatu atau semua hubungan atau kegiatan dari suatu segmen pada jaringan pribadi dengan jaringan luar yang bukan merupakan ruang lingkupnya [4].

\subsection{Virtual Local Area Network (VLAN)}

Sebuah kelompok device dalam sebuah LAN yang dikonfigurasi menggunakan software manajemen sehingga mereka dapat saling berkomunikasi asalkan dengan jaringan yang sama walaupun secara fiskal mereka berada pada segmen LAN yang berbeda [7].

\subsection{Electronic Document Management System (EDMS)}

Merupakan program perangkat lunak yang mengelola pembuatan, penyimpanan dan pengendalian dokumen secara elektronik. Fungsi utama EDMS adalah mengelola informasi elektronik dalam alur kerja organisasi. EDMS dasar harus mencakup pengelolaan dokumen, alur kerja, pengambilan teks, dan pencitraan serta mampu memberikan akses yang aman, menjaga konteks, dan mengeksekusi instruksi disposisi untuk semua catatan di sistem (www.edms.net) [8].

\section{ANALISIS DAN PERANCANGAN}

\subsection{Kebutuhan Fungsional}

Pada sistem jaringan di kantor proyek PHEONWJ dengan kondisi jaringan masih butuhnya perancangan topologi jaringan, maka kebutuhan sistem fungsional yang diperlukan antara lain yaitu:

a. Operator dapat mengontrol koneksi seluruh pengguna jaringan dengan menggunakan topologi star.

b. Pengguna dapat mengakses aplikasi secara langsung ke halaman intranet tanpa menggunakan jalur Citrix sehingga lalu lintas dokumen dapat lebih baik.

\subsection{Kebutuhan Non-Fungsional}

Dalam merancang sistem jaringan PHE ONWJ diperlukan kebutuhan non fungsional seperti:

1. Perangkat Keras (Hardware)
a. Modem Telkom ZTE ZXHN F609
b. Mikrotik RB 1100 AHX2
c. DLink DES-1210-52
d. Fengine 2200 
e. Komputer dengan spesifikasi minimal Core2Duo

2. Perangkat Lunak (Software)
a. Microsoft Windows
Professional (x64)
b. FreeMeter V.1.4.2710
c. Cisco Packet Tracer
d. WinBox 2.2
e. Citrix Receiver Ver.14.1.0.0
f. Java ${ }^{\mathrm{TM}} S E$ Development Kit 6 Update 45
g. Mozilla Firefox (x86) Ver.44
h. Internet
Ver.11.0.9600
i. Network Meter

3. Pengguna (Brainware)

Yang merupakan pengguna dari aplikasi Electronic Document Management System ini adalah para karyawan di PHE ONWJ Project Office, seperti bagian Document Control, HSSE, Engineer, $Q A / Q C$, Cost Control, Commissioning.

\subsection{Topologi Jaringan Yang Sedang Berjalan \\ Kondisi jaringan menggambarkan keadaan seluruh pengguna Electronic Document}

Management System secara langsung mengakses alamat dituju tanpa menggunakan routerboard sebagai media pengatur jaringan, seperti ilustrasi pada Gambar 1.

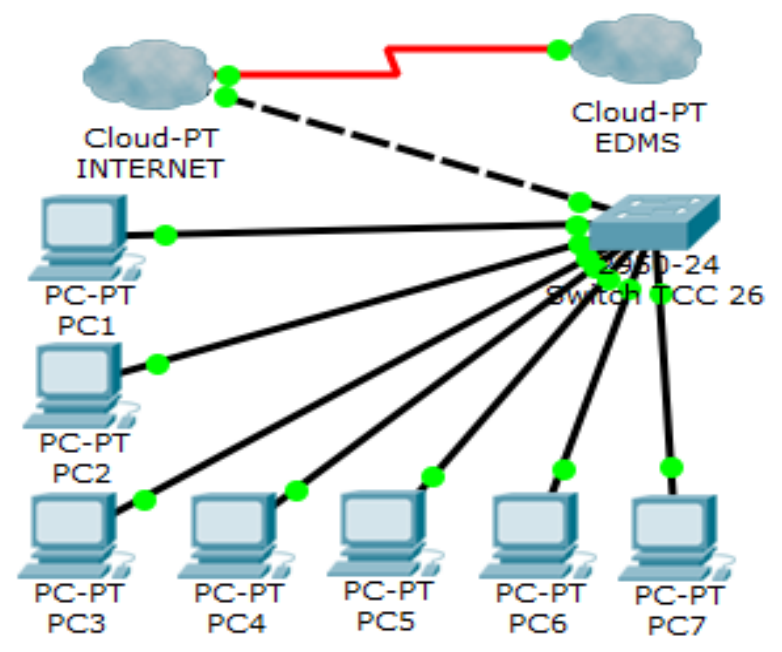

Gambar 1. Kondisi jaringan

Berdasarkan Gambar 1, pengguna harus memasukkan kode akun VPN masing-masing agar dapat mengakses aplikasi dengan bantuan piranti pembaca Citrix Receiver dan hasil ping pada Gambar 2 dan 3.

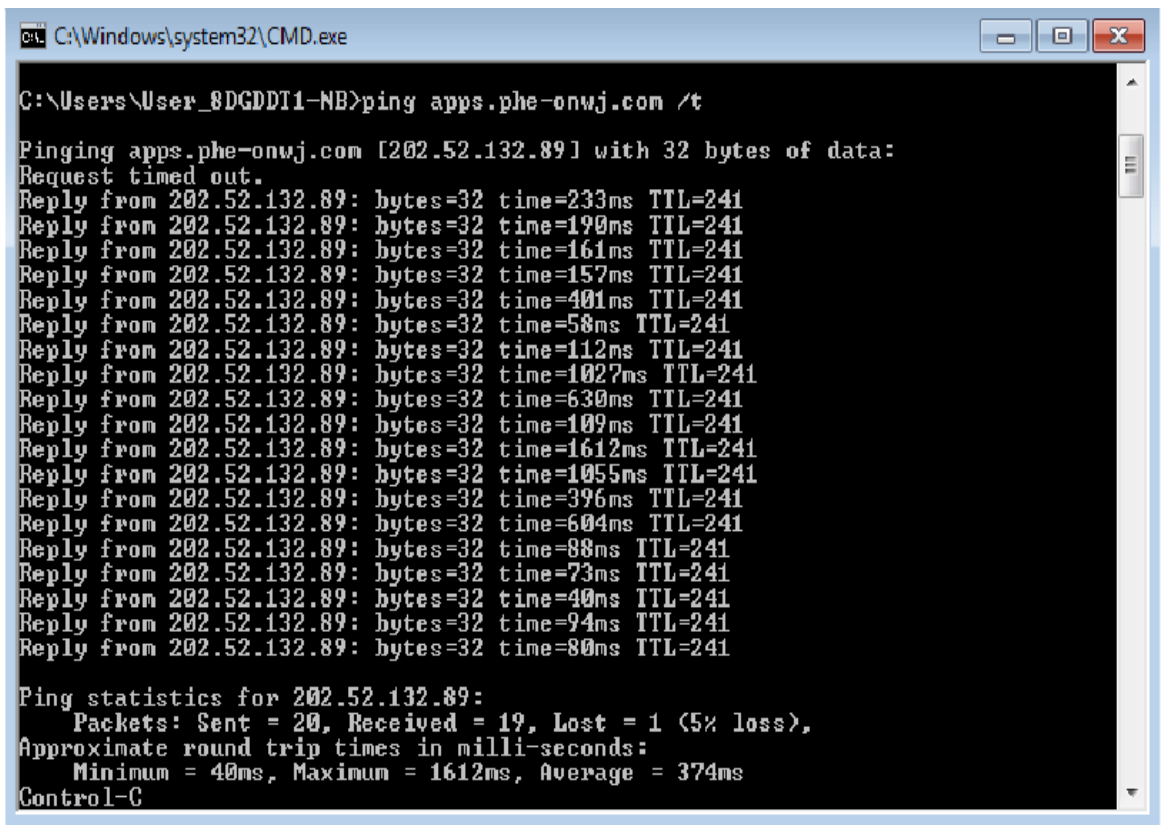

Gambar 2. Hasil ping menggunakan command prompt

Gambar 2, menggambarkan ping menggunakan Command Prompt mendapatkan hasil sebesar angka $1612 \mathrm{~ms}$, sedangkan
Gambar 3 menggambarkan ping menggunakan FreeMeter mendapatkan hasil sebesar 1060ms. 


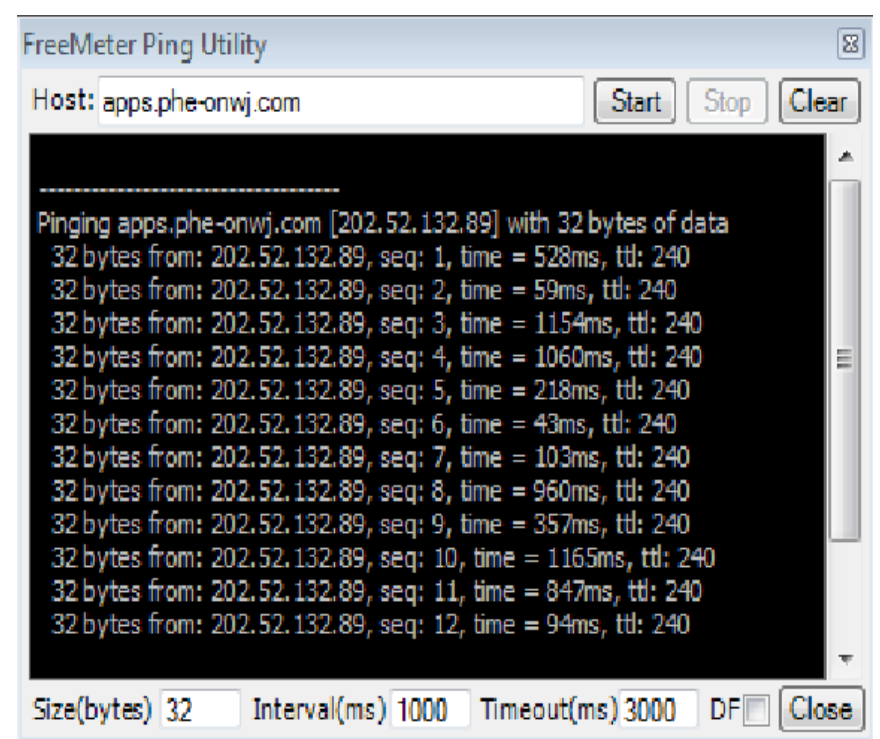

Gambar 3. Hasil ping menggunakan aplikasi FreeMeter

Namun dengan kondisi ping yang mencapai angka $1612 \mathrm{~ms}$, pengaksesan aplikasi sering mengalami hambatan. Hasil tracert ke aplikasi dapat dilihat pada Gambar 4.

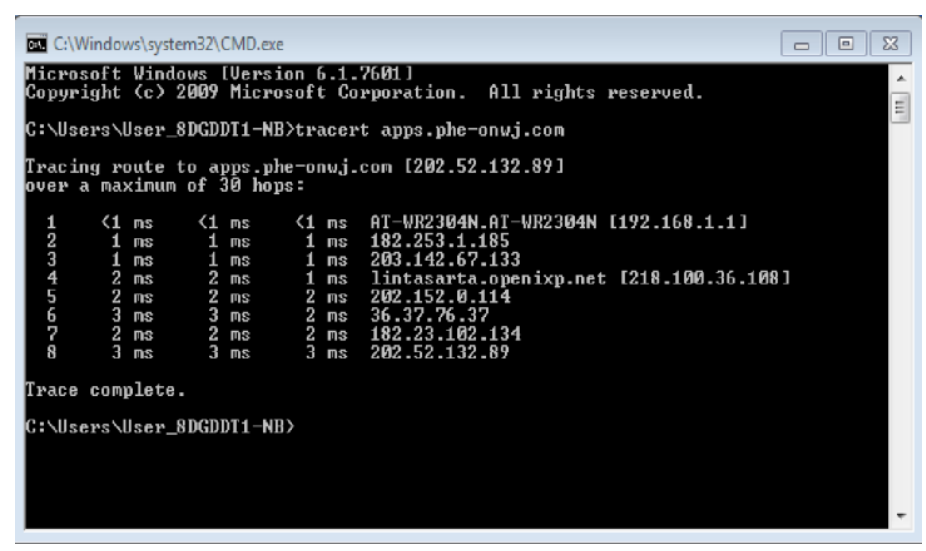

Gambar 4. Hasil tracert

\subsection{Perancangan Yang Diusulkan}

Penulis mencoba untuk merancang perancangan topologi yang lebih tepat guna memberikan solusi bagi permasalahan yang terjadi pada kantor proyek, salah satunya adalah dengan menggunakan topologi Hybrid. Kelebihan topologi Hybrid memiliki toleransi kesalahan yang lebih baik ketika sejumlah topologi berbeda terhubung ke satu sama lain dan tidak menghambat kerja dari jaringan lain ketika mengalami gangguan koneksi.

Dikarenakan hasil ping menggunakan Command Prompt dan FreeMeter mendapat angka diluar batas toleransi umum adalah 200$300 \mathrm{~ms}$. Ilustrasi perancangan dapat di lihat pada Gambar 5. 


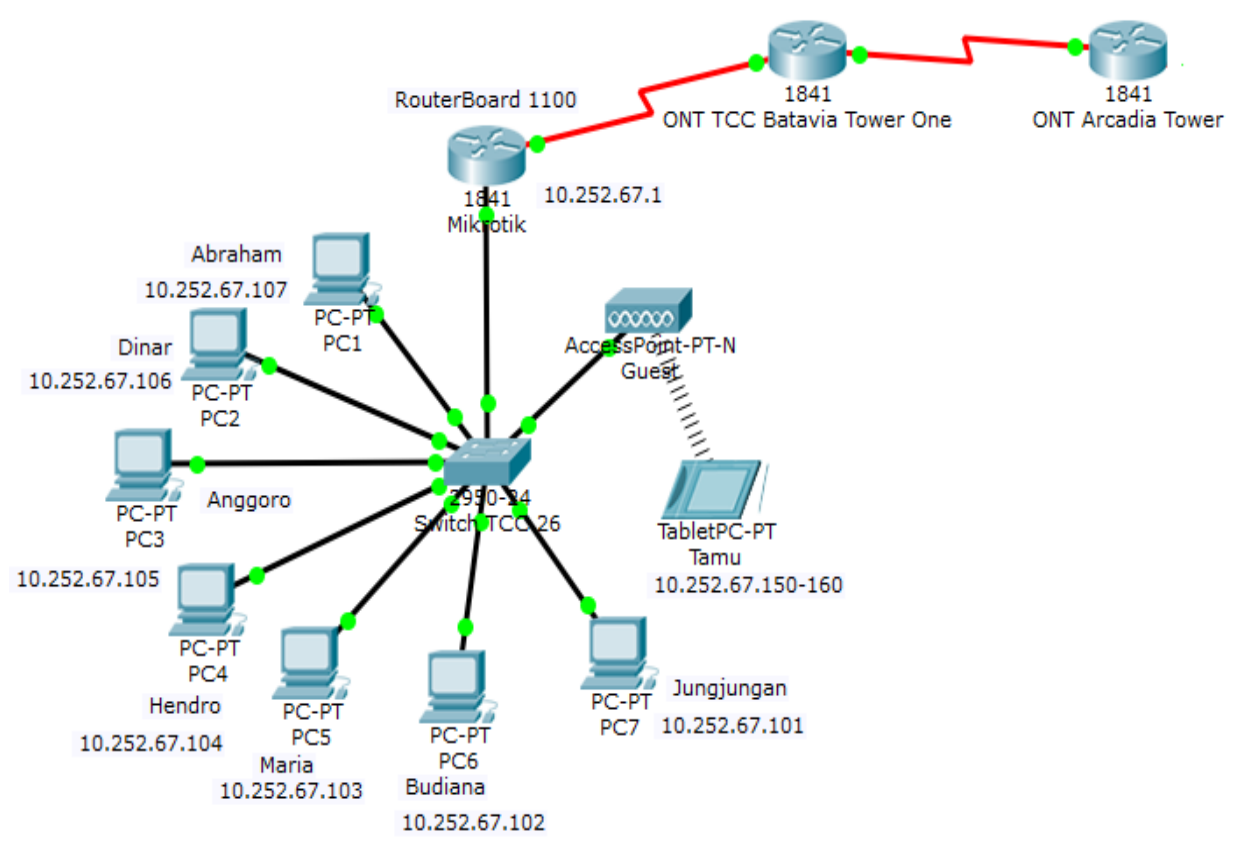

Gambar 5. Topologi yang diusulkan

Perancangan topologi yang diusulkan diterapkan agar memudahkan pendeteksian kesalahan yang terjadi ketika sedang mengalami kendala koneksi, memperkecil down time, memberikan keamanan lebih bagi pengguna jaringan dan memudahkan operator untuk melakukan perbaikan atau pun peremajaan.

\subsection{Konfigurasi Perangkat}

Diperlukannya routing perangkat antara sisi kantor pusat dan kantor proyek, dimana konfigurasi nya dapat dijabarkan pada Gambar 6,7, dan 8 .

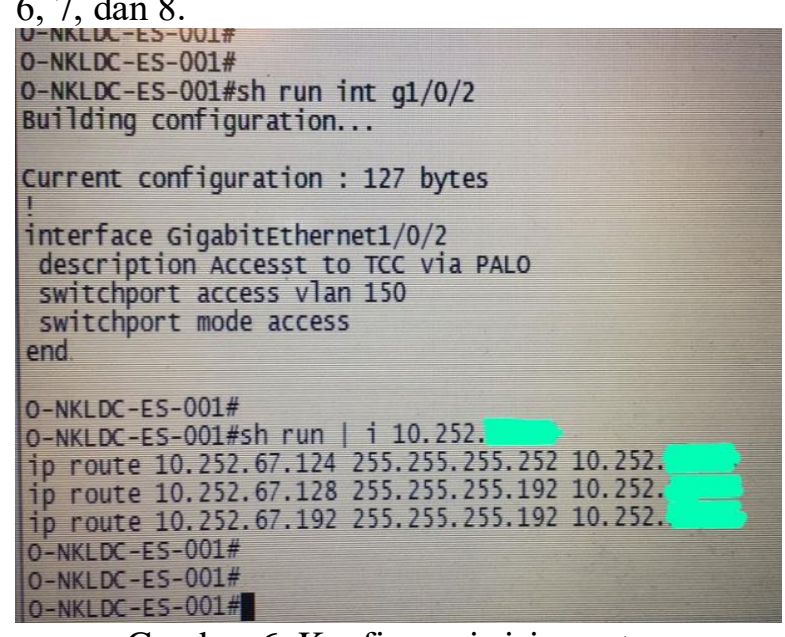

Gambar 6. Konfigurasi sisi pusat
Konfigurasi routing pada device pusat, bertujuan menghubungkan dua sisi jaringan dengan routing yang ditujukan ke alamat IP 10.252.67.124, 10.252.67.128, 10.252.67.192 sebagai IP Publik dengan Gateway 255.255.255.252 dan 255.255.255.192.

\begin{tabular}{|c|c|c|}
\hline DAC P10.252677.124/ & etherf Netro reschable & 0 \\
\hline$P 10.25267 .1288$ & 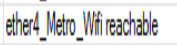 & 0 \\
\hline OAC P10.25267.1924 & 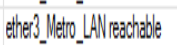 & 0 \\
\hline
\end{tabular}

Gambar 7. Konfigurasi sisi proyek

Konfigurasi device mikrotik pada area ke2 pada kantor proyek dan berfungsi menghubungkan routing dari device pusat. Dengan persamaan IP 10.252.67.124, 10.252.67.128, 10.252.67.192. Gateway terpasang pada port 3 , 4, dan 5 mikrotik. Penamaan dengan nama Metro_LAN, Metro_Wifi, Metro bertujuan untuk membantu admin dalam proses maintenance. 


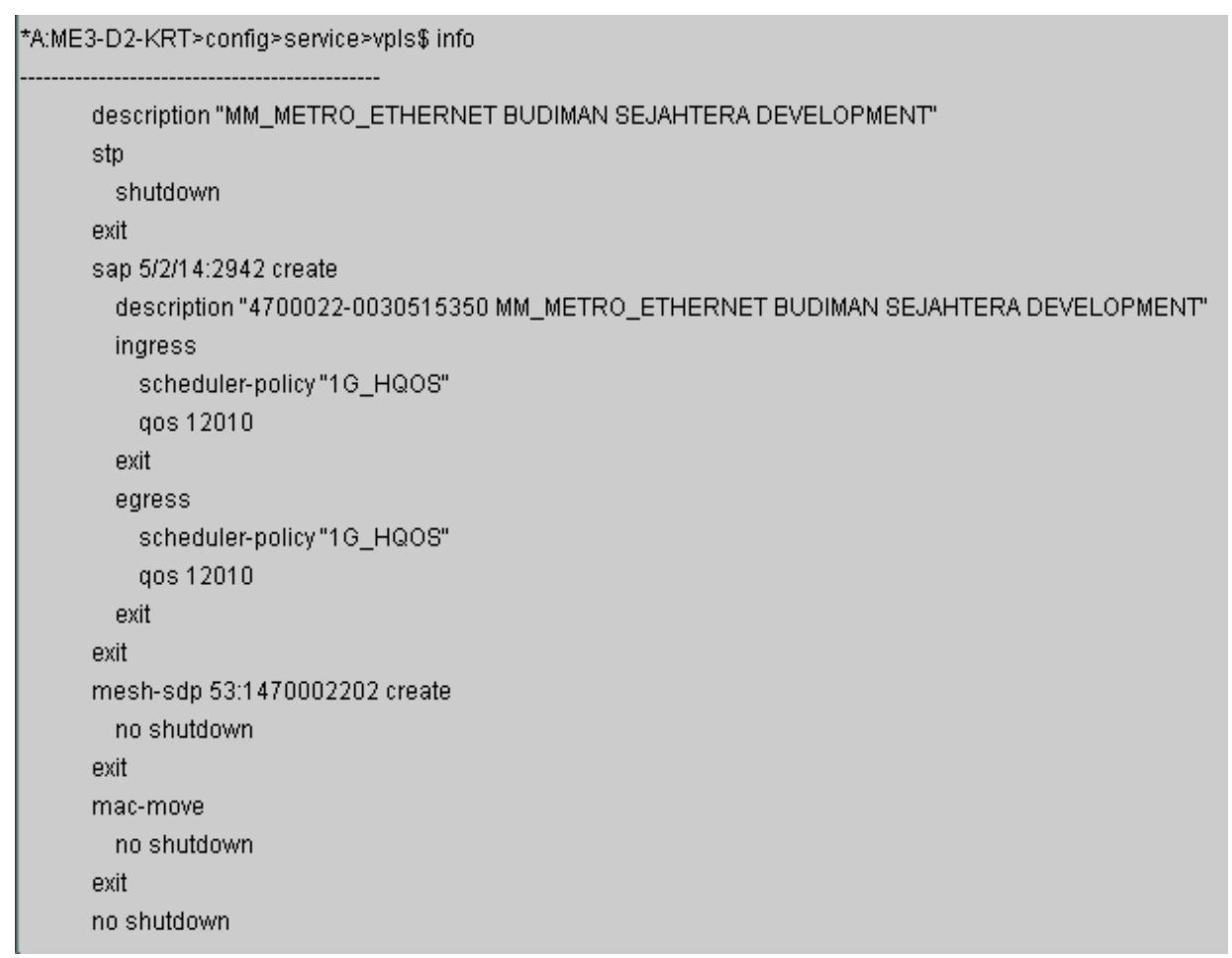

Gambar 8. Konfigurasi sisi Telkom

\subsection{Pengujian dan Hasil Akhir}

Penulis melakukan beberapa pengujian, diantaranya adalah pengujian baik dari sebelum topologi diterapkan maupun setelah topologi diterapkan, serta pengujian sebelum topologi diterapkan dengan dibebankan file, dan pengujian sesudah topologi diterapkan dengan dibebankan file. Pengujian dilakukan sebanyak 30 loop untuk memberikan hasil semaksimalnya dan membuktikan topologi Hybrid dapat mengoptimalisasi aplikasi EDMS. 


\begin{tabular}{|c|c|c|c|c|c|c|c|c|c|c|c|c|c|c|c|c|c|c|c|c|c|c|c|c|c|c|c|c|c|c|c|c|}
\hline \multirow{2}{*}{ Alamat IP } & \multicolumn{31}{|c|}{ Hop / lopp } & \multirow{2}{*}{$\begin{array}{c}\text { rata-rat } \\
\text { rmsits }\end{array}$} \\
\hline & & & 3 & 4 & $s$ & 6 & & $?$ & 8 & 9 & 10 & 11 & 12 & 13 & 14 & 15 & 16 & 17 & 18 & 19 & 20 & 21 & 22 & 23 & \begin{tabular}{|l|l|}
3 & 24 \\
\end{tabular} & 25 & 26 & 27 & 28 & 29 & 30 & \\
\hline 1025267.150 & 0 & 3 & 61 & 4 & 21 & 0 & & 6 & 4 & 14 & 6 & 3 & 3 & 5 & 3 & 7 & 4 & 3 & 131 & 3 & 0 & 4 & 3 & 3 & \begin{tabular}{|l|l|}
3 & 3 \\
\end{tabular} & 3 & 3 & 3 & 3 & 3 & 4 & 10,43333 \\
\hline 1025267.151 & 3 & 42 & 10 & 10 & 3 & 40 & & 2 & 3 & 3 & 3 & 3 & 3 & 3 & 3 & 69 & 7 & 3 & 7 & 3 & 33 & s & 12 & 3 & 3 & 3 & 7 & 28 & 11 & 11 & 7 & 11,56667 \\
\hline 1025267.152 & 3 & 5 & 6 & 40 & 3 & 3 & 19 & 19 & 69 & 0 & 34 & 38 & 3 & 12 & 18 & 3 & 7 & 3 & 25 & 3 & 4 & 3 & 36 & 4 & \begin{tabular}{|l|l|}
4 & 35 \\
\end{tabular} & 6 & 3 & 3 & 3 & 12 & 23 & 15,53333 \\
\hline 1025267.153 & 3 & 11 & 16 & 3 & 8 & 3 & & 3 & 2 & 3 & 3 & 3 & 3 & 3 & 63 & 7 & 3 & 7 & 3 & 34 & 3 & 3 & 4 & 4 & 4 & 9 & 31 & 6 & \begin{tabular}{|l|}
18 \\
\end{tabular} & 3 & 4 & \begin{tabular}{|l|}
9,066667 \\
\end{tabular} \\
\hline 1023267.154 & 3 & 3 & 11 & 2 & 30 & 4 & 21 & 11 & 3 & 3 & 3 & 3 & 3 & 3 & 3 & 2 & 10 & 3 & 15 & 3 & 19 & 3 & 2 & 3 & 5 & 3 & 4 & 3 & 3 & 3 & 4 & 6,6666677 \\
\hline 1025267.155 & 6 & 7 & 13 & 11 & 3 & 3 & 11 & 11 & 4 & 13 & 3 & 7 & 4 & 29 & 3 & \begin{tabular}{|l|}
11 \\
\end{tabular} & 79 & 20 & 3 & 5 & 5 & 29 & 6 & 0 & 3 & 3 & 3 & 3 & 3 & 3 & 8 & 10,03333 \\
\hline 1025267.156 & 6 & 30 & 3 & 3 & 7 & 2 & & 3 & 3 & 20 & 3 & 3 & 49 & 3 & 3 & 3 & 7 & 3 & 3 & 4 & 3 & 5 & 3 & 8 & 4 & 13 & 4 & 26 & 3 & 5 & 4 & $\begin{array}{l}7,566657 \\
\end{array}$ \\
\hline 10.35267 .197 & 3 & 4 & 4 & 22 & 9 & 5 & & 4 & 18 & 12 & 5 & 3 & 8 & 3 & 26 & 3 & 57 & 74 & 19 & 4 & 3 & 2 & 25 & 4 & \begin{tabular}{|l|l|}
4 & 11 \\
\end{tabular} & 3 & 5 & 5 & 4 & 19 & 3 & 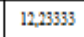 \\
\hline 1025267.158 & 3 & 3 & 3 & 3 & 3 & 3 & & 3 & 4 & 44 & 3 & 22 & 3 & 43 & 4 & 11 & 4 & 30 & 3 & 69 & 3 & 15 & 3 & 28 & 6 & 6 & 5 & 3 & 91 & 3 & 3 & 14,3 \\
\hline 1025267.159 & 3 & 3 & 4 & 3 & 3 & 32 & & 3 & 9 & 3 & 24 & 3 & 13 & 7 & 3 & 3 & 3 & 0 & 4 & 10 & 3 & 23 & 4 & 4 & 4 & 5 & 4 & 4 & 12 & 3 & 3 & 6,866667 \\
\hline 10.23267 .160 & 3 & 21 & 0 & $s$ & 31 & 5 & & 9 & 4 & 24 & 2 & 9 & 19 & 3 & 3 & 3 & 0 & 3 & 10 & 3 & 29 & 3 & 3 & 4 & \begin{tabular}{|l|l|}
4 & 73 \\
\end{tabular} & 5 & 45 & 0 & 3 & 47 & 3 & 12,46667 \\
\hline 1025267.161 & 3 & 50 & 3 & 3 & 3 & 3 & 24 & 84 & 3 & 3 & 4 & 4 & 49 & 22 & 3 & 3 & 3 & 3 & 3 & $n$ & 14 & 0 & 3 & 8 & 3 & 12 & 4 & 39 & 8 & 3 & 3 & 10,26667 \\
\hline 1025267.162 & 8 & 9 & 3 & 3 & 7 & 3 & 39 & 392 & 26 & 8 & 2 & 36 & 3 & 15 & 3 & 2 & 3 & 50 & 3 & 3 & 77 & 21 & 3 & 6 & 6 & 30 & 4 & 10 & 5 & 4 & 3 & 13,16667 \\
\hline 10232267.163 & 9 & 10 & 3 & 3 & 3 & 14 & 13 & 13 & $?$ & 28 & 3 & 45 & 17 & 28 & 3 & 9 & 3 & 3 & 3 & 3 & 3 & 3 & 4 & 10 & 5 & 3 & 3 & 3 & 3 & 3 & 6 & \begin{tabular}{|l|l|}
8,666667 \\
\end{tabular} \\
\hline 1022267.164 & 13 & 10 & 6 & 10 & 3 & 3 & & 3 & 3 & 3 & 3 & 3 & 3 & 40 & 3 & 19 & 7 & 4 & 4 & 45 & 0 & 3 & 6 & 3 & 8 & 6 & 134 & 5 & 3 & 4 & 3 & 12,06667 \\
\hline 1025267.165 & 0 & 4 & $s$ & 0 & 35 & 8 & 19 & 19 & 3 & 68 & 3 & 3 & 3 & 57 & 3 & 95 & 3 & 4 & 5 & 52 & 0 & 3 & $?$ & 3 & 3 & 3 & 3 & 3 & 4 & 3 & 13 & 13,9 \\
\hline 1025267.166 & 4 & 23 & 4 & 8 & 5 & 3 & & 7 & 3 & 12 & 4 & 0 & 19 & 3 & 0 & 0 & 2 & 3 & 3 & 3 & 4 & 6 & 3 & 12 & \begin{tabular}{|l|l|}
2 & 10 \\
\end{tabular} & 4 & 5 & 11 & 3 & 64 & 16 & \begin{tabular}{|l|l|}
8,133333 \\
\end{tabular} \\
\hline 1023267.167 & 3 & 20 & 30 & 7 & 30 & 6 & 11 & 11 & 3 & 3 & 3 & 3 & 3 & 10 & 6 & 3 & 3 & 3 & 3 & 4 & 3 & 3 & 3 & 3 & 3 & 3 & 4 & 52 & 3 & 3 & 3 & \begin{tabular}{|l|l|}
8,66567 \\
\end{tabular} \\
\hline 1023267.168 & 3 & 15 & 28 & 5 & 3 & 8 & 3 & 3 & 3 & 3 & 12 & 3 & 3 & 3 & 56 & 8 & 35 & 13 & 61 & 3 & 3 & 3 & 51 & 4 & \begin{tabular}{|l|l|}
4 & 90 \\
\end{tabular} & 3 & 7 & 3 & 49 & 5 & 4 & \begin{tabular}{|l|l|}
1633333 \\
\end{tabular} \\
\hline 10222.67 .169 & 4 & 5 & 14 & 44 & 7 & 6 & & 3 & 3 & 7 & 3 & 4 & 17 & 6 & 3 & 3 & 5 & 3 & 0 & 73 & 5 & 29 & 7 & 3 & 6 & 3 & 40 & 3 & 5 & 3 & 68 & 12,86667 \\
\hline 3225717 & 3 & 4 & 3 & 10 & 73 & $?$ & 21 & 21 & 8 & 3 & 3 & 3 & 8 & 22 & 3 & 7 & 4 & 3 & 7 & 3 & 3 & 4 & 3 & 3 & 5 & 3 & 72 & 7 & 3 & 22 & 3 & \begin{tabular}{|l|l|}
10,33333 \\
\end{tabular} \\
\hline
\end{tabular}

\begin{tabular}{|c|c|c|c|c|c|c|c|c|c|c|c|c|c|c|c|c|c|c|c|c|c|c|c|c|c|c|c|c|c|c|c|}
\hline $10: 22267.171$ & 3 & 4 & 45 & 12 & 3 & 6 & 3 & 17 & 3 & 8 & 3 & 3 & 3 & 3 & 2 & 3 & 3 & 43 & 3 & 15 & 3 & 3 & 145 & 5 & 8 & 21 & 43 & 12 & 5 & 8 & 14,56667 \\
\hline 1267.172 & 7 & 3 & 3 & 3 & 3 & 49 & 3 & 3 & 3 & 6 & s & 3 & 21 & 14 & 3 & 0 & 3 & 3 & 6 & 62 & 3 & 101 & 5 & 0 & 13 & 4 & 24 & 3 & 3 & 3 & 12,06667 \\
\hline 102252.67 .177 & 4 & 39 & 14 & 3 & 10 & 6 & 8 & 3 & 3 & 16 & 3 & 3 & 6 & 3 & 3 & 0 & 3 & 3 & 32 & 47 & 3 & 3 & 38 & 4 & 7 & 4 & 10 & 3 & 3 & 4 & 9,6 \\
\hline 1025267.174 & 6 & 3 & 3 & 4 & 3 & 6 & 3 & 3 & 10 & 3 & 3 & 3 & 3 & 4 & 6 & 3 & 6 & 5 & 0 & 4 & 14 & $?$ & 3 & 3 & 0 & 15 & 3 & $?$ & 3 & 3 & 4,8333333 \\
\hline 1023267.175 & 0 & 34 & 15 & 3 & 4 & 4 & $?$ & 9 & 0 & 3 & 3 & 15 & 3 & 4 & 3 & 3 & 24 & 31 & 4 & 3 & 40 & 5 & 11 & 6 & 15 & 3 & 4 & 3 & 43 & 3 & 10,33333 \\
\hline 10252.67 .177 & 3 & 30 & 3 & 6 & 3 & 7 & 5 & 57 & 3 & 3 & 3 & 3 & 8 & 4 & 3 & 5 & 3 & 3 & 3 & 0 & 3 & 66 & 3 & 0 & 8 & 3 & 10 & ? & 136 & 4 & 13,16667 \\
\hline 1025267.17 & 3 & 30 & 3 & 8 & 10 & 5 & 64 & 10 & 4 & 3 & 17 & $s$ & 3 & 3 & 3 & 4 & 9 & 21 & 3 & 15 & 3 & 3 & 2 & 13 & 3 & 3 & 2 & 3 & 8 & 5 & 10,6 \\
\hline 1025267.178 & 6 & 4 & 3 & 3 & 3 & 3 & 3 & 33 & 19 & 3 & 3 & 4 & 4 & 3 & 3 & 11 & 3 & 4 & 15 & $n$ & 3 & 8 & 3 & 3 & 34 & 22 & 8 & 12 & 38 & 12 & 13,23333 \\
\hline & 3 & 3 & 3 & 8 & 3 & 4 & 13 & 5 & 59 & 6 & 3 & 6 & 3 & 16 & 3 & 3 & 3 & 3 & 0 & 3 & 3 & 4 & 59 & 4 & 97 & 3 & 3 & 3 & 30 & 3 & 11,96667 \\
\hline
\end{tabular}

Gambar 9. Pengujian sebelum topologi diterapkan 


\begin{tabular}{|c|c|c|c|c|c|c|c|c|c|c|c|c|c|c|c|c|c|c|c|c|c|c|c|c|c|c|c|c|c|c|c|c|c|}
\hline \multirow{2}{*}{ Alamat IP } & \multicolumn{32}{|c|}{ Hop/bop } & \multirow{2}{*}{$\begin{array}{c}\text { rata-rsta } \\
(\mathrm{mrs})\end{array}$} \\
\hline & 1 & 2 & 3 & 4 & 5 & 6 & & & 8 & 9 & 10 & 11 & 12 & 13 & & 14 & 18 & 16 & 17 & 18 & 19 & 20 & 21 & 22 & 23 & 24 & 25 & 26 & 27 & 28 & 29 & 30 & \\
\hline 10.252 .67 .150 & 5 & 3 & 7 & 3 & 5 & $?$ & 22 & 2 & 19 & 3 & 4 & 11 & 0 & 8 & & 5 & 7 & 17 & 7 & 7 & 6 & 6 & 11 & 7 & 5 & 15 & 15 & 13 & 7 & 6 & 225 & 10 & 15,73333 \\
\hline 10.252 .67 .151 & 193 & 5 & 5 & 6 & 4 & 6 & 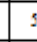 & 3 & 8 & 4 & 16 & 6 & 5 & 8 & & 24 & 8 & 8 & 5 & 10 & 6 & 12 & 4 & 153 & 4 & 3 & 11 & 7 & 15 & 9 & 3 & 6 & 18,76667 \\
\hline 1025267.152 & 6 & 12 & 8 & 3 & 4 & $?$ & : & 3 & $?$ & 12 & 6 & 0 & 8 & 16 & & 11 & 9 & 19 & 5 & $?$ & 6 & 3 & 8 & 3 & 15 & 16 & 15 & 6 & 6 & 225 & 10 & $?$ & 13,63333 \\
\hline 10.252 .67 .153 & 6 & 9 & 5 & $?$ & 7 & 9 & 6 & 6 & 11 & $s$ & 9 & 4 & 11 & 14 & & 11 & 6 & 6 & 8 & 5 & 5 & 6 & 231 & 6 & 6 & 5 & 14 & 8 & 7 & 6 & 5 & 5 & 14,76667 \\
\hline 10.252 .67 .154 & 23 & 15 & 6 & 6 & 12 & $?$ & 23 & & 11 & 9 & 265 & 7 & 6 & 15 & & 7 & 6 & 15 & 6 & 8 & $s$ & 5 & 4 & 6 & 5 & 6 & 3 & 9 & 6 & 6 & 7 & 9 & 17,33333 \\
\hline 1025267.159 & 5 & 6 & 16 & 6 & 5 & 5 & 10 & & 11 & 8 & 13 & 17 & 3 & 6 & & 12 & 7 & $s$ & 7 & 5 & 6 & 5 & 5 & 3 & 10 & 6 & 3 & 8 & 6 & 15 & 7 & 6 & 9,1 \\
\hline 1025267.156 & 5 & 13 & 10 & $?$ & 4 & 4 & 7 & 6 & 5 & 5 & 5 & 15 & 5 & 8 & & 15 & 3 & 4 & 6 & 6 & 6 & 3 & 5 & 6 & 9 & 5 & 5 & 4 & 4 & 8 & 1115 & 12 & 10,4 \\
\hline 10.252 .67 .157 & 12 & 14 & 3 & 4 & 6 & 8 & 16 & 6 & 10 & 8 & 4 & 15 & 6 & 6 & & 15 & 14 & 5 & 13 & 5 & 293 & 6 & 7 & 12 & 6 & 18 & 3 & 6 & 16 & 9 & 4 & 12 & 18,666677 \\
\hline 1025267.158 & 5 & 7 & 6 & 15 & 5 & 3 & 8 & 8 & 8 & 4 & 6 & 3 & 18 & 7 & & 0 & 7 & 6 & 3 & $?$ & 10 & 3 & 16 & 6 & 17 & 8 & 8 & 6 & 14 & 3 & 6 & 12 & 7.9 \\
\hline 1025267.199 & 5 & 8 & 6 & 4 & 6 & 3 & 9 & 9 & 13 & 4 & 4 & 3 & 6 & $?$ & & $?$ & 3 & 6 & 9 & $?$ & ${ }^{7}$ & $2 m$ & 5 & 8 & 11 & 5 & 19 & 5 & 6 & 8 & 12 & 6 & 16,16667 \\
\hline 10252.67 .160 & 4 & 11 & 8 & 3 & 11 & 3 & 14 & & 6 & 5 & 8 & 8 & $?$ & $s$ & & 6 & & 5 & 5 & 3 & 20 & 3 & 8 & 20 & 16 & 4 & 6 & 6 & 8 & 131 & 14 & 10 & 12,46667 \\
\hline 1025267.161 & 5 & 7 & 8 & 10 & 19 & 8 & 0 & 0 & 0 & 7 & 6 & 6 & 6 & 7 & & 5 & 10 & 15 & 13 & 6 & \begin{tabular}{l|l}
6 \\
\end{tabular} & 225 & 10 & 20 & 13 & 5 & 4 & 10 & 6 & 17 & 11 & 3 & 13,66657 \\
\hline 1025267.162 & 12 & 7 & 3 & 4 & 10 & 4 & 3 & 72 & 26 & 7 & 6 & 6 & 9 & 3 & & 5 & 8 & 9 & 29 & 6 & 9 & 14 & 6 & 7 & \begin{tabular}{|l|}
6 \\
\end{tabular} & 5 & 3 & 13 & 162 & 6 & 13 & 22 & 14,433333 \\
\hline 1025267.163 & 31 & 11 & 5 & 3 & 4 & 0 & & 8 & 5 & 13 & 16 & 3 & $?$ & 5 & & 5 & 11 & 8 & 4 & 14 & 16 & 14 & 6 & 6 & 225 & \begin{tabular}{|l|}
10 \\
\end{tabular} & 19 & 12 & $?$ & 18 & 16 & 6 & 17,13333 \\
\hline 10252.67 .164 & 12 & 6 & 8 & 11 & 6 & 3 & 8 & 8 & 35 & 6 & 5 & 3 & 9 & 6 & & 12 & \begin{tabular}{l|l}
6 & 1 \\
\end{tabular} & 168 & 6 & 19 & 12 & 11 & 6 & 11 & 6 & 5 & 14 & 11 & 7 & 14 & 10 & 6 & 14,86667 \\
\hline 1025267.165 & 14 & 8 & 6 & 3 & 9 & 6 & 14 & 4 & 0 & 7 & 6 & 6 & 11 & 7 & & 4 & 15 & 21 & 9 & 8 & 8 & 6 & 15 & 6 & 6 & 12 & 10 & 17 & 27 & 7 & 15 & 10 & 9,8333333 \\
\hline 10252.67 .166 & 6 & 15 & 6 & 6 & 4 & $?$ & $=$ & 3 & $?$ & 5 & 8 & 7 & 7 & 6 & 27 & 7 & $?$ & 7 & 12 & 10 & 17 & 4 & 6 & 7 & 12 & 6 & 3 & 14 & 7 & 17 & 36 & 5 & 18,03333 \\
\hline 1025267.167 & $s$ & 9 & $n$ & 339 & 6 & 3 & $1:$ & 2 & $?$ & 6 & 10 & 10 & 5 & 10 & & 6 & 7 & 5 & 9 & 10 & 14 & 6 & 10 & 3 & 5 & 19 & 194 & 8 & 14 & 10 & 8 & 15 & 26 \\
\hline 1025267.168 & 10 & 4 & 5 & 5 & 6 & 6 & 3 & 6 & $?$ & 7 & 4 & 6 & 5 & 14 & & \begin{tabular}{l|l}
5 & 2 \\
\end{tabular} & 200 & 5 & ${ }^{7}$ & 15 & 9 & 0 & 14 & 24 & 5 & 13 & \begin{tabular}{|l|}
0 \\
\end{tabular} & 18 & 14 & 60 & 16 & 3 & 16,56667 \\
\hline 10252.67 .169 & 8 & 5 & 11 & 8 & 0 & 8 & 1 & 6 & 10 & 6 & 11 & 6 & 7 & 5 & & \begin{tabular}{l|l}
6 & \\
\end{tabular} & 6 & 5 & 10 & 21 & 8 & 8 & 8 & 3 & 13 & 9 & 8 & 14 & 10 & 7 & 13 & 10 & 8,733333 \\
\hline 10232.67 .170 & 4 & 14 & 0 & 8 & 5 & 13 & 1 & 3 & 7 & 8 & 6 & 5 & 12 & 11 & & 6 & $?$ & 9 & 9 & 5 & 25 & 21 & 5 & 12 & 10 & 6 & \begin{tabular}{|l|}
14 \\
\end{tabular} & \begin{tabular}{|l|}
6 \\
\end{tabular} & 5 & 12 & 10 & 3 & 8,8333333 \\
\hline 10252.67 .171 & 12 & 9 & 7 & 7 & 10 & 6 & 1 & 4 & 8 & 6 & 3 & 5 & 3 & 6 & & 8 & 5 & 5 & 0 & 37 & 3 & 11 & 7 & 6 & 12 & 9 & 6 & 15 & 9 & 18 & 13 & 91 & 11,9 \\
\hline 1025267.172 & $?$ & 0 & 0 & 6 & 6 & s & 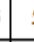 & 5 & 8 & 3 & 9 & 16 & 14 & 6 & & $\begin{array}{ll}6 & 2 \\
\end{array}$ & 225 & 10 & 20 & 14 & 6 & 16 & 11 & 6 & 17 & 10 & 6 & 16 & 8 & 3 & 13 & 27 & 16,76667 \\
\hline 10222267.173 & $?$ & 8 & 8 & 8 & 8 & 8 & 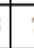 & 7 & 8 & 8 & 8 & 7 & 0 & 25 & & 13 & 6 & 7 & 37 & 5 & 11 & $?$ & 6 & 12 & 9 & 7 & 15 & 9 & 16 & 14 & 60 & 28 & 12,4 \\
\hline 1025267.174 & 4 & 4 & $?$ & 8 & $?$ & 3 & & 8 & 9 & 7 & $?$ & 276 & $?$ & $?$ & & 12 & 5 & 18 & 3 & 6 & 8 & 12 & 8 & 3 & 13 & 9 & 6 & 14 & 35 & 7 & 13 & 9 & 18,03333 \\
\hline 10.252 .67 .175 & 4 & 7 & 6 & 4 & 11 & 3 & 1 & 9 & 5 & $?$ & 6 & 4 & 8 & $s$ & & 6 & 16 & 14 & 6 & 6 & 225 & 10 & 6 & 18 & 10 & 18 & 32 & 8 & 7 & 15 & 12 & ${ }^{16}$ & 17,2 \\
\hline 1023267.176 & 4 & 6 & 3 & 5 & 5 & 4 & 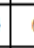 & 6 & 5 & 262 & 7 & 3 & 9 & 6 & & 14 & 3 & 18 & 13 & 9 & 6 & 13 & 8 & 3 & 13 & 37 & 5 & 15 & 9 & 7 & 13 & 79 & 19,93333 \\
\hline 1022267.17 & 10 & $?$ & 9 & 17 & 5 & $s$ & 1 & 0 & 8 & 5 & 5 & 14 & 5 & 9 & & 19 & 6 & 3 & 4 & 6 & 11 & 148 & 14 & 3 & 5 & 14 & 10 & 21 & 14 & 8 & 3 & 11 & 13,33333 \\
\hline 1025267.178 & 4 & 5 & $?$ & 8 & 5 & 10 & 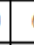 & 6 & 4 & 8 & 246 & $\stackrel{9}{2}$ & 6 & 9 & & 6 & 13 & 5 & 8 & 13 & 7 & 4 & 13 & $?$ & 16 & 11 & 3 & 32 & 9 & 8 & 14 & 9 & 16,9 \\
\hline 0232 & 6 & 8 & 12 & 7 & 6 & 10 & & 9 & 5 & 9 & 6 & 7 & 6 & 3 & & 16 & 9 & 5 & 10 & ${ }^{7}$ & 4 & \begin{tabular}{|l|}
19 \\
\end{tabular} & 194 & 7 & 14 & 10 & 20 & 16 & 8 & 19 & 14 & 8 & 15,86667 \\
\hline
\end{tabular}

Gambar 10. Pengujian sesudah topologi diterapkan 


\begin{tabular}{|c|c|c|c|c|c|c|c|c|c|c|c|c|c|c|c|c|c|c|c|c|c|c|c|c|c|c|c|c|c|c|c|c|c|}
\hline \multirow{2}{*}{ Alamat IP } & \multicolumn{32}{|c|}{ Hop / bop } & \multirow{2}{*}{$\begin{array}{l}\text { rats- } \\
\text { rat } \\
(\mathrm{ms})\end{array}$} \\
\hline & 1 & 3 & 3 & 4 & 5 & & & 7 & & 9 & 10 & & 12 & 13 & 14 & 15 & 16 & 17 & 1 & & 19 & 20 & 21 & 22 & 23 & 24 & & ${ }_{26}$ & 27 & 28 & 29 & 30 & \\
\hline $\begin{array}{l}10: 322.67 . \\
130\end{array}$ & $\begin{array}{r}11 \\
2\end{array}$ & 2 & 35 & 38 & 69 & 99 & $\begin{array}{l}11 \\
\frac{11}{3}\end{array}$ & $\begin{array}{c}13 \\
3\end{array}$ & $\begin{array}{r}14 \\
4\end{array}$ & $\begin{array}{c}26 \\
7\end{array}$ & \begin{tabular}{|c|}
28 \\
0
\end{tabular} & $\begin{array}{l}35 \\
0\end{array}$ & 370 & 382 & 320 & 441 & 626 & 336 & 29 & \begin{tabular}{l|l}
92 & 2
\end{tabular} & 229 & 392 & 357 & 424 & 427 & 567 & $\begin{array}{c}50 \\
8 \\
8\end{array}$ & 650 & 950 & 450 & 579 & $\begin{array}{r}108 \\
0\end{array}$ & $\begin{array}{c}364+16 \\
67\end{array}$ \\
\hline 10.252 .67$. & 39 & 6 & 36 & 18 & $\begin{array}{r}12 \\
4\end{array}$ & $\begin{array}{l}12 \\
4 \\
4\end{array}$ & 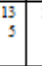 & $\begin{array}{c}{ }^{21} \\
7\end{array}$ & \begin{tabular}{c|}
14 \\
2
\end{tabular} & $\begin{array}{r}22 \\
8\end{array}$ & $\begin{array}{r}24 \\
9 \\
9\end{array}$ & $\begin{array}{c}25 \\
0\end{array}$ & 245 & \begin{tabular}{|l|l|}
194 \\
\end{tabular} & 215 & \begin{tabular}{|l|l|}
465 \\
\end{tabular} & 525 & 274 & 27 & & 127 & 296 & 398 & \begin{tabular}{|l|}
518 \\
\end{tabular} & 403 & 496 & \begin{tabular}{|c|}
58 \\
3
\end{tabular} & 792 & 599 & 450 & \begin{tabular}{r|r}
119 \\
2
\end{tabular} & 516 & 335,1 \\
\hline $\begin{array}{l}10.252 .67 . \\
1522 .\end{array}$ & $3^{3}$ & $s$ & 33 & $s 8$ & $\begin{array}{c}15 \\
15\end{array}$ & $\begin{array}{l}1 \\
1\end{array}$ & $\begin{array}{r}12 \\
9 \\
\end{array}$ & $\begin{array}{c}14 \\
3 \\
\end{array}$ & $\begin{array}{r}29 \\
8\end{array}$ & $\begin{array}{l}23 \\
5\end{array}$ & \begin{tabular}{r|}
29 \\
9 \\
\end{tabular} & $\begin{array}{l}32 \\
3\end{array}$ & 372 & 330 & 357 & 625 & 320 & 274 & 21. & & 324 & 330 & 427 & 417 & 559 & 496 & $\begin{array}{r}64 \\
0 \\
04\end{array}$ & 913 & 429 & 635 & $\begin{array}{r}105 \\
9\end{array}$ & 200 & $\begin{array}{c}344,23 \\
33\end{array}$ \\
\hline $\begin{array}{l}10252.67 . \\
153\end{array}$ & 5 & 23 & 45 & $\begin{array}{c}13 \\
1\end{array}$ & $\begin{array}{c}16 \\
1\end{array}$ & $\begin{array}{l}16 \\
1\end{array}$ & $\begin{array}{r}24 \\
1 \\
\end{array}$ & \begin{tabular}{|r|}
18 \\
3
\end{tabular} & ${ }_{7}^{23}$ & $\begin{array}{r}29 \\
6\end{array}$ & \begin{tabular}{|c|}
$\begin{array}{r}29 \\
3\end{array}$ \\
\end{tabular} & $\begin{array}{r}30 \\
1\end{array}$ & $25 s$ & 272 & \begin{tabular}{|l|l|}
368 \\
\end{tabular} & 603 & 164 & 303 & 20 & & 370 & 287 & $s s 2$ & 402 & 533 & 586 & \begin{tabular}{|c|}
99 \\
5
\end{tabular} & 694 & 435 & \begin{tabular}{|r|}
101 \\
6
\end{tabular} & 731 & \begin{tabular}{l|l|}
378 \\
\end{tabular} & 364,5 \\
\hline $\begin{array}{l}10.352 .67 . \\
1.54\end{array}$ & 71 & 35 & 98 & $\begin{array}{r}11 \\
2\end{array}$ & 32 & 12 & $\begin{array}{r}17 \\
0 \\
\end{array}$ & $\begin{array}{r}20 \\
4 \\
4\end{array}$ & 88 & $\begin{array}{l}32 \\
0 \\
0\end{array}$ & $\begin{array}{l}? \\
? \\
9\end{array}$ & $\begin{array}{r}39 \\
4\end{array}$ & 391 & 402 & 792 & 268 & 0 & 437 & 54 & & 336 & 591 & 834 & 393 & 739 & 927 & $\begin{array}{r}4 \\
4 \\
4\end{array}$ & 349 & 221 & 163 & 456 & 394 & $\begin{array}{c}357,93 \\
33\end{array}$ \\
\hline $\begin{array}{l}1025267 . \\
1.55\end{array}$ & 43 & 0 & $\begin{array}{r}\begin{array}{r}26 \\
2\end{array} \\
\end{array}$ & $\begin{array}{r}45 \\
5\end{array}$ & 32 & $\frac{1}{9}$ & 87 & $\begin{array}{r}42 \\
4 \\
4\end{array}$ & $\begin{array}{c}54 \\
1\end{array}$ & $\begin{array}{r}27 \\
8\end{array}$ & $\begin{array}{c}222 \\
5\end{array}$ & 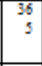 & 90 & 437 & 472 & \begin{tabular}{|l|l}
336 \\
\end{tabular} & 488 & 516 & 10 & 5 & 487 & 438 & $\begin{array}{r}M_{2}^{11} \\
\end{array}$ & 349 & 393 & 196 & \begin{tabular}{r|}
32 \\
9
\end{tabular} & 521 & 501 & 504 & 624 & 0 & $\begin{array}{l}893,56 \\
67\end{array}$ \\
\hline $\begin{array}{l}10.352 .67 \\
1.56\end{array}$ & 59 & $\begin{array}{c}15 \\
8\end{array}$ & $8 s$ & ${ }^{21}$ & $\begin{array}{l}24 \\
0\end{array}$ & . & $\frac{13}{8}$ & \begin{tabular}{r|}
30 \\
1
\end{tabular} & $\begin{array}{c}33 \\
2 \\
\end{array}$ & $\begin{array}{c}38 \\
1\end{array}$ & $\begin{array}{c}32 \\
9 \\
9\end{array}$ & $\begin{array}{r}41 \\
3\end{array}$ & 851 & 302 & 0 & 437 & 548 & 536 & 59 & & 334 & 393 & 740 & 928 & 444 & 349 & $\begin{array}{r}22 \\
1 \\
1\end{array}$ & 166 & 443 & 394 & 438 & 573 & $\begin{array}{c}394,86 \\
67\end{array}$ \\
\hline $\begin{array}{l}1025267 . \\
157\end{array}$ & 28 & 47 & 3 & $\begin{array}{c}10 \\
2\end{array}$ & 21 & 1 & $\begin{array}{c}21 \\
8 \\
\end{array}$ & \begin{tabular}{r|}
37 \\
6
\end{tabular} & $\begin{array}{c}77 \\
6\end{array}$ & $\begin{array}{l}29 \\
29\end{array}$ & \begin{tabular}{|l|}
30 \\
8 \\
\end{tabular} & 59 & 458 & \begin{tabular}{|l|l|}
588 \\
\end{tabular} & 238 & 2226 & 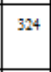 & 134 & 43 & & 500 & 366 & 517 & 443 & sss & 403 & $\begin{array}{r}45 \\
3\end{array}$ & \begin{tabular}{|c|}
112 \\
6
\end{tabular} & 352 & 399 & 198 & 0 & $\begin{array}{c}326,76 \\
67\end{array}$ \\
\hline $\begin{array}{l}10.322 .67 \\
1.58\end{array}$ & 65 & 67 & $\begin{array}{c}17 \\
4\end{array}$ & 71 & $\begin{array}{c}23 \\
3\end{array}$ & 3 & $\begin{array}{l}24 \\
7 \\
7\end{array}$ & $\begin{array}{c}13 \\
8 \\
\end{array}$ & \begin{tabular}{r|}
32 \\
4 \\
4
\end{tabular} & $\begin{array}{l}27 \\
5\end{array}$ & $\begin{array}{c}39 \\
5\end{array}$ & $\begin{array}{l}39 \\
1\end{array}$ & 402 & \begin{tabular}{|l|l|}
791 \\
\end{tabular} & 290 & 156 & 295 & 285 & 42 & & 256 & 431 & 572 & 545 & 651 & 757 & \begin{tabular}{r|r}
31 & \\
4 &
\end{tabular} & 667 & 842 & 383 & 398 & 357 & $\begin{array}{c}372,83 \\
33\end{array}$ \\
\hline $\begin{array}{l}10.252 .277 . \\
1.99\end{array}$ & 34 & 99 & 38 & 76 & 72 & 2 & $\begin{array}{r}18 \\
1\end{array}$ & $\begin{array}{r}23 \\
0\end{array}$ & $\begin{array}{r}36 \\
1\end{array}$ & $\begin{array}{r}26 \\
1\end{array}$ & $\begin{array}{l}27 \\
6\end{array}$ & $\begin{array}{r}29 \\
6\end{array}$ & 111 & 452 & \begin{tabular}{|l|l|}
557 \\
\end{tabular} & \begin{tabular}{|l|}
293 \\
\end{tabular} & 210 & 330 & 12 & & 416 & 485 & 351 & 501 & $s 31$ & $\begin{array}{r}100 \\
7\end{array}$ & \begin{tabular}{r|r}
47 \\
9
\end{tabular} & 437 & \begin{tabular}{r|r|}
122 & \\
1
\end{tabular} & 342 & 399 & 352 & $\begin{array}{c}346,93 \\
33\end{array}$ \\
\hline 10.252 .67$. & 29 & $\begin{array}{c}13 \\
4 \\
\end{array}$ & \begin{tabular}{|c|}
23 \\
3
\end{tabular} & $\frac{13}{7}$ & $\begin{array}{c}28 \\
4\end{array}$ & $\begin{array}{l}8 \\
4 \\
\end{array}$ & $\begin{array}{c}30 \\
1 \\
30\end{array}$ & \begin{tabular}{r|}
$\begin{array}{r}21 \\
4\end{array}$ \\
\end{tabular} & $\begin{array}{l}38 \\
9 \\
\end{array}$ & $\begin{array}{l}38 \\
8\end{array}$ & $\begin{array}{r}40 \\
6\end{array}$ & 99 & 245 & 60 & 255 & 372 & 344 & 518 & 42 & & 933 & 506 & 735 & 0 & 363 & 235 & $\begin{array}{l}15 \\
7\end{array}$ & 444 & 547 & 410 & 566 & 260 & $\begin{array}{c}339.66 \\
67\end{array}$ \\
\hline $\begin{array}{l}1023257 . \\
161\end{array}$ & 0 & $\begin{array}{r}26 \\
1 \\
\end{array}$ & $\begin{array}{l}47 \\
0\end{array}$ & $\begin{array}{l}28 \\
28 \\
0\end{array}$ & 97 & 97 & $\begin{array}{r}44 \\
0 \\
\end{array}$ & $\begin{array}{c}35 \\
7\end{array}$ & $\begin{array}{c}29 \\
3\end{array}$ & $\begin{array}{l}20 \\
2\end{array}$ & $\begin{array}{l}36 \\
5\end{array}$ & 90 & \begin{tabular}{|l|l} 
& 403
\end{tabular} & \begin{tabular}{|l|l|} 
\\
\end{tabular} & 351 & 502 & 531 & $\begin{array}{r}100 \\
7\end{array}$ & 47 & 77 & 437 & \begin{tabular}{|r|}
$m_{2}$ \\
\end{tabular} & 350 & 399 & 199 & 0 & \begin{tabular}{r|}
34 \\
7
\end{tabular} & 408 & 18 & 342 & 0 & 249 & 355,9 \\
\hline $\begin{array}{l}10.252 .67 . \\
1.62\end{array}$ & $\begin{array}{c}15 \\
4 \\
\end{array}$ & \begin{tabular}{c|c|}
28 \\
8
\end{tabular} & \begin{tabular}{|c|}
12 \\
2
\end{tabular} & \begin{tabular}{|c|}
27 \\
1
\end{tabular} & 31 & 3 & $\begin{array}{l}19 \\
9 \\
9\end{array}$ & \begin{tabular}{r|r}
36 \\
1
\end{tabular} & $\begin{array}{r}37 \\
2\end{array}$ & $\begin{array}{l}41 \\
9 \\
9\end{array}$ & \begin{tabular}{|l|}
67 \\
6
\end{tabular} & $\begin{array}{r}23 \\
0\end{array}$ & 46 & 239 & 397 & 314 & 503 & 420 & 8. & & 556 & 908 & 705 & 450 & $\begin{array}{r}1000 \\
6\end{array}$ & 749 & $\begin{array}{l}40 \\
9 \\
9\end{array}$ & 288 & 385 & 432 & $5: 4$ & 0 & $\begin{array}{c}409,23 \\
33\end{array}$ \\
\hline $\begin{array}{l}10252267 . \\
103\end{array}$ & $\begin{array}{c}14 \\
7\end{array}$ & $\begin{array}{c}266 \\
7\end{array}$ & $\begin{array}{c}28 \\
0\end{array}$ & 9 & & $\begin{array}{l}37 \\
1\end{array}$ & $\begin{array}{c}38 \\
1\end{array}$ & $\begin{array}{l}32 \\
0 \\
0\end{array}$ & \begin{tabular}{r|r}
44 \\
1
\end{tabular} & $\begin{array}{c}62 \\
6\end{array}$ & $\begin{array}{l}33 \\
6\end{array}$ & $\begin{array}{r}29 \\
2\end{array}$ & 245 & 367 & $\mid 359$ & \begin{tabular}{|l|l|}
17 \\
\end{tabular} & \begin{tabular}{|l}
436 \\
\end{tabular} & 567 & 50 & 28 & 649 & 944 & 454 & 566 & $\begin{array}{c}107 \\
8\end{array}$ & 200 & 39 & 323 & 253 & $s 11$ & 444 & 531 & 435,3 \\
\hline $\begin{array}{l}10.25267 . \\
1.64\end{array}$ & $\begin{array}{c}14 \\
2\end{array}$ & $\begin{array}{r}22 \\
8\end{array}$ & \begin{tabular}{|c|}
25 \\
1
\end{tabular} & $\begin{array}{l}25 \\
0\end{array}$ & $\begin{array}{r}24 \\
8\end{array}$ & 8 & $\begin{array}{l}17 \\
8 \\
\end{array}$ & $\begin{array}{r}20 \\
0\end{array}$ & $\begin{array}{r}47 \\
1\end{array}$ & $\begin{array}{l}52 \\
3\end{array}$ & $\begin{array}{l}27 \\
4\end{array}$ & $\begin{array}{l}27 \\
6\end{array}$ & 126 & 282 & 466 & 310 & \begin{tabular}{|l|l}
417 \\
\end{tabular} & 526 & 38 & & 525 & 361 & 463 & $\begin{array}{r}124 \\
4\end{array}$ & 417 & 399 & $\begin{array}{c}26 \\
4 \\
4\end{array}$ & 369 & 560 & 318 & 491 & 674 & $\begin{array}{c}417,96 \\
67\end{array}$ \\
\hline $\begin{array}{l}10252267 . \\
1053\end{array}$ & $\begin{array}{r}30 \\
2 \\
\end{array}$ & $\begin{array}{c}36 \\
3\end{array}$ & \begin{tabular}{|c|}
33 \\
9
\end{tabular} & $\begin{array}{l}18 \\
5\end{array}$ & & $\begin{array}{l}42 \\
3\end{array}$ & $\begin{array}{c}39 \\
3\end{array}$ & \begin{tabular}{r|}
30 \\
2 \\
\end{tabular} & \begin{tabular}{|c|}
25 \\
5
\end{tabular} & 74 & \begin{tabular}{|l}
30 \\
6
\end{tabular} & $\begin{array}{r}38 \\
1\end{array}$ & 356 & 467 & 570 & 501 & 622 & 850 & 43 & & 742 & 957 & 433 & 338 & 250 & 170 & $\begin{array}{c}45 \\
7 \\
7\end{array}$ & 394 & 437 & 573 & 275 & 4 & 4229 \\
\hline $\begin{array}{l}10252267 . \\
106\end{array}$ & 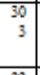 & 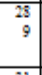 & $\begin{array}{r}35 \\
6 \\
\end{array}$ & $\begin{array}{l}12 \\
3\end{array}$ & & $\begin{array}{l}11 \\
6 \\
6\end{array}$ & $\begin{array}{l}44 \\
6 \\
4\end{array}$ & $\begin{array}{c}61 \\
7 \\
7\end{array}$ & $\begin{array}{r}24 \\
0 \\
0\end{array}$ & $\begin{array}{c}23 \\
5\end{array}$ & 32 & $\begin{array}{l}14 \\
8\end{array}$ & 390 & \begin{tabular}{|l|l|} 
& 546
\end{tabular} & 410 & 537 & \begin{tabular}{|l|l}
457 \\
\end{tabular} & 914 & 42 & & 479 & $\begin{array}{r}116 \\
7\end{array}$ & 354 & 398 & 198 & 399 & $\begin{array}{c}56 \\
2\end{array}$ & 491 & 513 & 597 & 435 & 0 & 414,8 \\
\hline $\begin{array}{l}10.25267 . \\
167\end{array}$ & \begin{tabular}{c|}
22 \\
7
\end{tabular} & $\begin{array}{r}31 \\
6 \\
\end{array}$ & \begin{tabular}{|c|}
37 \\
2
\end{tabular} & 9 & & 要 & $\begin{array}{r}42 \\
0\end{array}$ & \begin{tabular}{|c|}
88 \\
8
\end{tabular} & \begin{tabular}{|c|}
28 \\
8
\end{tabular} & $\begin{array}{l}25 \\
4\end{array}$ & 74 & ${ }^{27}$ & 381 & 339 & 439 & 579 & \begin{tabular}{|l|l}
457 \\
|
\end{tabular} & $\mid 609$ & 86 & & 422 & 735 & 943 & 418 & 348 & $m 2$ & $\begin{array}{l}16 \\
2\end{array}$ & 435 & $\$ 47$ & 411 & 560 & 0 & $\begin{array}{c}417.36 \\
67\end{array}$ \\
\hline 10258267. & \begin{tabular}{c|}
22 \\
7
\end{tabular} & $\begin{array}{r}33 \\
9 \\
9\end{array}$ & $\begin{array}{r}30 \\
6\end{array}$ & 6 & & $\begin{array}{l}11 \\
8 \\
8\end{array}$ & $\begin{array}{c}12 \\
2\end{array}$ & $\begin{aligned} 45 \\
5 \\
\end{aligned}$ & \begin{tabular}{r|r|}
63 \\
1
\end{tabular} & $\begin{array}{l}25 \\
2\end{array}$ & \begin{tabular}{|r}
26 \\
4
\end{tabular} & $\begin{array}{r}34 \\
8\end{array}$ & 192 & 437 & 530 & 451 & 569 & 499 & 93 & & 455 & 507 & \begin{tabular}{r|}
115 \\
5
\end{tabular} & 399 & 367 & 234 & $\begin{array}{c}36 \\
0\end{array}$ & 513 & 460 & 463 & 636 & 439 & $\begin{array}{c}434.26 \\
67\end{array}$ \\
\hline $\begin{array}{l}10252.67 . \\
1.99\end{array}$ & \begin{tabular}{c|}
16 \\
8 \\
\end{tabular} & \begin{tabular}{|c|}
12 \\
5
\end{tabular} & \begin{tabular}{|l|}
30 \\
7
\end{tabular} & $\frac{24}{5}$ & 3 & 8 & $\begin{array}{c}37 \\
8\end{array}$ & \begin{tabular}{r|}
44 \\
1
\end{tabular} & $\begin{array}{r}76 \\
1\end{array}$ & $\begin{array}{l}29 \\
0\end{array}$ & $\begin{array}{l}12 \\
8\end{array}$ & $\begin{array}{c}30 \\
3\end{array}$ & 285 & \begin{tabular}{|l|l|} 
& 10 \\
\end{tabular} & 486 & 417 & 556 & 541 & 64 & & 788 & 314 & 657 & 834 & 399 & 372 & \begin{tabular}{|r|}
40 \\
3
\end{tabular} & 444 & 647 & 574 & 399 & 450 & $\begin{array}{c}445,25 \\
67\end{array}$ \\
\hline $\begin{array}{l}10252267 . \\
170\end{array}$ & \begin{tabular}{c|}
28 \\
8
\end{tabular} & \begin{tabular}{r|}
32 \\
8
\end{tabular} & 98 & $\begin{array}{l}10 \\
8\end{array}$ & & $\begin{array}{l}48 \\
5\end{array}$ & $\begin{array}{l}60 \\
3 \\
3\end{array}$ & \begin{tabular}{|c|}
25 \\
2 \\
\end{tabular} & $\begin{array}{c}25 \\
7\end{array}$ & $\begin{array}{r}32 \\
6\end{array}$ & \begin{tabular}{|l}
14 \\
7
\end{tabular} & $\begin{array}{r}39 \\
0\end{array}$ & 547 & 407 & $s 22$ & 452 & 1999 & 403 & 45 & 84 & $\begin{array}{r}1133 \\
6\end{array}$ & 354 & 394 & 199 & 329 & 521 & \begin{tabular}{l|}
50 \\
1
\end{tabular} & 505 & 622 & 451 & 0 & 224 & 406,4 \\
\hline $\begin{array}{l}10.25267 \\
171\end{array}$ & $\begin{array}{c}37 \\
5\end{array}$ & $\begin{array}{r}31 \\
9\end{array}$ & $\begin{array}{r}24 \\
6\end{array}$ & 42 & & 19 & $\begin{array}{c}30 \\
3 \\
\end{array}$ & \begin{tabular}{|c|}
25 \\
5
\end{tabular} & 73 & $\begin{array}{r}28 \\
8\end{array}$ & $\begin{array}{r}39 \\
7\end{array}$ & $\begin{array}{l}37 \\
0\end{array}$ & 473 & 561 & 450 & 622 & 550 & \begin{tabular}{|l|l|} 
& 436
\end{tabular} & 74 & 42 & 998 & 433 & 338 & 249 & 170 & 456 & $\begin{array}{c}56 \\
1\end{array}$ & 423 & 572 & 276 & 4 & 101 & $\begin{array}{c}421.56 \\
67\end{array}$ \\
\hline $\begin{array}{l}10252267 . \\
172\end{array}$ & $\begin{array}{r}r 0 \\
6 \\
\end{array}$ & $\begin{array}{r}32 \\
4 \\
4\end{array}$ & 96 & $\begin{array}{l}48 \\
7\end{array}$ & & 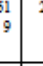 & $\begin{array}{c}26 \\
7 \\
7\end{array}$ & $\begin{array}{r}24 \\
4 \\
\end{array}$ & $\begin{array}{r}r 2 \\
6\end{array}$ & $\begin{array}{r}14 \\
7\end{array}$ & $\begin{array}{l}39 \\
3\end{array}$ & $\begin{array}{c}54 \\
7\end{array}$ & \begin{tabular}{|l|l} 
& 099
\end{tabular} & 538 & 466 & 915 & 450 & \begin{tabular}{|l|l|}
493 \\
\end{tabular} & & $\begin{array}{c}18 \\
3 \\
\end{array}$ & 355 & 399 & 196 & 0 & 347 & 402 & 18 & 342 & 307 & 209 & 224 & 145 & 371,8 \\
\hline $\begin{array}{l}10252267 . \\
173\end{array}$ & $\begin{array}{r}32 \\
8\end{array}$ & $\begin{array}{r}22 \\
3\end{array}$ & $\begin{array}{r}39 \\
4\end{array}$ & $\begin{array}{l}86 \\
6\end{array}$ & & 3 & $\begin{array}{r}222 \\
4\end{array}$ & 45 & $\begin{array}{r}28 \\
2\end{array}$ & $\begin{array}{l}36 \\
8\end{array}$ & 31 & $\begin{array}{l}43 \\
8\end{array}$ & 595 & 520 & 672 & \begin{tabular}{|l}
518 \\
\end{tabular} & 350 & 725 & 91 & 16 & 430 & 336 & 200 & 424 & 444 & 590 & \begin{tabular}{r|}
42 \\
3
\end{tabular} & 573 & 275 & 4 & 101 & 350 & $\begin{array}{r}418,96 \\
67\end{array}$ \\
\hline $\begin{array}{l}10225267 . \\
174\end{array}$ & \begin{tabular}{|l|}
30 \\
7
\end{tabular} & \begin{tabular}{r|}
38 \\
8
\end{tabular} & \begin{tabular}{|r|}
42 \\
2 \\
\end{tabular} & $\begin{array}{r}48 \\
4\end{array}$ & $\begin{array}{r}27 \\
4\end{array}$ & 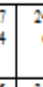 & \begin{tabular}{r|}
24 \\
6 \\
\end{tabular} & \begin{tabular}{|c|}
35 \\
2
\end{tabular} & 40 & $\begin{array}{r}39 \\
0\end{array}$ & \begin{tabular}{|r|}
49 \\
4
\end{tabular} & \begin{tabular}{|c|}
38 \\
3 \\
\end{tabular} & 518 & 527 & \begin{tabular}{|c|}
102 \\
7
\end{tabular} & \begin{tabular}{|l|}
448 \\
\end{tabular} & 394 & $\begin{array}{r}1110 \\
\mathrm{~s}\end{array}$ & 31 & & 373 & 360 & 355 & 572 & 0 & 18 & 0 & 199 & 162 & 531 & 239 & 127 & 375 \\
\hline 3267. & \begin{tabular}{r|}
68 \\
4 \\
\end{tabular} & $\begin{array}{r}23 \\
0\end{array}$ & 45 & $\begin{array}{r}24 \\
0\end{array}$ & $\begin{array}{c}35 \\
7\end{array}$ & 5 & $\begin{array}{r}31 \\
4 \\
1\end{array}$ & $\begin{array}{c}50 \\
2\end{array}$ & $\begin{array}{r}41 \\
2\end{array}$ & $\begin{array}{r}51 \\
8\end{array}$ & $\begin{array}{l}50 \\
8\end{array}$ & $\begin{array}{r}91 \\
3 \\
\end{array}$ & 719 & 450 & \begin{tabular}{|r|}
100 \\
6 \\
\end{tabular} & 745 & 395 & 288 & 38 & & 432 & 584 & $s s 2$ & 623 & 537 & 431 & 26 & 331 & 397 & 194 & 98 & 77 & 432,1 \\
\hline $\begin{array}{l}1025267 . \\
176\end{array}$ & \begin{tabular}{c|}
53 \\
5
\end{tabular} & $\begin{array}{r}39 \\
7\end{array}$ & \begin{tabular}{|c|}
32 \\
7
\end{tabular} & $\begin{array}{r}28 \\
4\end{array}$ & 32 & $\begin{array}{l}2 \\
7\end{array}$ & 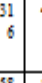 & $\begin{array}{l}42 \\
0\end{array}$ & \begin{tabular}{|c|}
45 \\
7
\end{tabular} & $\begin{array}{r}51 \\
8\end{array}$ & \begin{tabular}{|c|}
43 \\
3
\end{tabular} & \begin{tabular}{|r|}
50 \\
8 \\
\end{tabular} & $\begin{array}{r}100 \\
3\end{array}$ & 453 & 473 & $\begin{array}{r}111 \\
2\end{array}$ & 226 & 381 & 35 & & 281 & 521 & 451 & 534 & 541 & 408 & 0 & 223 & 145 & 27 & 244 & 525 & $\begin{array}{c}421.36 \\
67\end{array}$ \\
\hline $\begin{array}{l}1025267 . \\
177\end{array}$ & $\begin{array}{r}40 \\
4 \\
\end{array}$ & $\begin{array}{c}66 \\
3\end{array}$ & 0 & \begin{tabular}{|c|}
31 \\
3
\end{tabular} & $\begin{array}{l}43 \\
6\end{array}$ & $\begin{array}{l}3 \\
6 \\
6\end{array}$ & \begin{tabular}{|l|}
88 \\
9 \\
\end{tabular} & \begin{tabular}{r|}
53 \\
6
\end{tabular} & $\begin{array}{l}59 \\
9\end{array}$ & $\begin{array}{r}83 \\
4\end{array}$ & \begin{tabular}{|l}
399 \\
4
\end{tabular} & \begin{tabular}{|c|}
73 \\
9
\end{tabular} & 927 & 444 & 348 & 220 & 162 & 444 & |39 & & 437? & 572 & 261 & 110 & 92 & 351 & \begin{tabular}{r|}
15 \\
1
\end{tabular} & 140 & 169 & 159 & 293 & $s 11$ & $\begin{array}{c}359,73 \\
33\end{array}$ \\
\hline $\begin{array}{l}10225267 . \\
178\end{array}$ & $\begin{array}{r}40 \\
6\end{array}$ & $\begin{array}{c}38 \\
1\end{array}$ & \begin{tabular}{|r|}
42 \\
6 \\
\end{tabular} & $\begin{array}{c}24 \\
1\end{array}$ & ${ }_{3}^{26}$ & $\frac{6}{3}$ & $\begin{array}{r}34 \\
0\end{array}$ & \begin{tabular}{r|}
29 \\
9
\end{tabular} & $\begin{array}{r}40 \\
3\end{array}$ & \begin{tabular}{|r|}
50 \\
4
\end{tabular} & \begin{tabular}{|c|}
56 \\
1
\end{tabular} & $\begin{array}{r}46 \\
4 \\
4\end{array}$ & 545 & \begin{tabular}{|r|}
100 \\
0
\end{tabular} & 4533 & $\mid 456$ & $\begin{array}{r}110 \\
7\end{array}$ & 260 & & $0:$ & 510 & 818 & 332 & 452 & 9 & 333 & \begin{tabular}{|r|}
41 \\
3
\end{tabular} & 199 & 210 & 137 & 260 & 241 & 407,5 \\
\hline 202267. & $\begin{array}{r}37 \\
0\end{array}$ & $\begin{array}{r}43 \\
2\end{array}$ & \begin{tabular}{|c|}
74 \\
5 \\
\end{tabular} & $\begin{array}{c}27 \\
5\end{array}$ & $\begin{array}{c}11 \\
4\end{array}$ & $\begin{array}{l}1 \\
4 \\
4\end{array}$ & 8 & $\begin{array}{r}27 \\
3 \\
\end{array}$ & $\begin{array}{c}39 \\
7 \\
7\end{array}$ & $\begin{array}{r}49 \\
0\end{array}$ & $\begin{array}{r}41 \\
4\end{array}$ & $\begin{array}{r}56 \\
3\end{array}$ & 513 & 796 & 731 & 303 & 681 & 843 & |38 & & 359 & 388 & 416 & 617 & $\$ 42$ & 701 & $\begin{array}{l}60 \\
0 \\
0\end{array}$ & 110 & 70 & 372 & 396 & 118 & $\begin{array}{c}441,65 \\
67\end{array}$ \\
\hline
\end{tabular}

Gambar 11. Pengujian sebelum topologi diterapkan dengan beban pengetesan 


\begin{tabular}{|c|c|c|c|c|c|c|c|c|c|c|c|c|c|c|c|c|c|c|c|c|c|c|c|c|c|c|c|c|c|c|c|}
\hline \multirow{2}{*}{ Alamat IP } & \multicolumn{30}{|c|}{ Hop/bop } & \multirow{2}{*}{$\begin{array}{c}\text { rats- } \\
\text { rata } \\
(\mathrm{mz})\end{array}$} \\
\hline & 1 & 2 & 3 & 4 & 5 & 6 & 7 & 8 & 9 & 10 & 11 & 12 & 13 & 14 & 15 & 16 & 17 & 18 & 19 & 20 & 21 & 22 & 23 & 24 & 25 & 26 & 27 & 28 & 29 & 30 & \\
\hline $0^{10.252 .67 .15}$ & $\begin{array}{r}22 \\
5\end{array}$ & $\begin{array}{r}63 \\
8 \\
\end{array}$ & \begin{tabular}{r|}
42 \\
3
\end{tabular} & \begin{tabular}{r|}
11 \\
2
\end{tabular} & $\begin{array}{c}12 \\
3\end{array}$ & $\begin{array}{r}65 \\
6 \\
\end{array}$ & $\begin{array}{r}47 \\
4\end{array}$ & $\begin{array}{r}31 \\
5\end{array}$ & $\begin{array}{r}21 \\
3\end{array}$ & \begin{tabular}{r|}
21 \\
5
\end{tabular} & 39 & 99 & 37 & \begin{tabular}{r|}
20 \\
6
\end{tabular} & $\begin{array}{r}61 \\
5\end{array}$ & \begin{tabular}{r|}
12 \\
2
\end{tabular} & $\begin{array}{r}57 \\
1\end{array}$ & 28 & 30 & \begin{tabular}{r|}
10 \\
6
\end{tabular} & 15 & \begin{tabular}{r|}
19 \\
1
\end{tabular} & 30 & \begin{tabular}{|c|}
13 \\
5
\end{tabular} & $\begin{array}{r}22 \\
7\end{array}$ & $\begin{array}{r}40 \\
7\end{array}$ & 57 & 29 & 20 & 36 & $\begin{array}{l}231,466 \\
7\end{array}$ \\
\hline $\begin{array}{l}10.252 .67 .15 \\
1\end{array}$ & 0 & $\begin{array}{r}17 \\
7 \\
\end{array}$ & \begin{tabular}{r|r}
71 \\
1
\end{tabular} & \begin{tabular}{r|r|}
52 & \\
9 &
\end{tabular} & \begin{tabular}{r|r}
45 \\
5
\end{tabular} & $\begin{array}{r}26 \\
6 \\
\end{array}$ & \begin{tabular}{r|}
26 \\
6
\end{tabular} & 49 & \begin{tabular}{r|r|}
15 & \\
2 & \\
\end{tabular} & $\begin{array}{r}14 \\
3 \\
\end{array}$ & 29 & $\begin{array}{r}69 \\
5\end{array}$ & 47 & $\begin{array}{r}65 \\
8 \\
\end{array}$ & 20 & \begin{tabular}{r|}
13 \\
2
\end{tabular} & \begin{tabular}{r|}
20 \\
9
\end{tabular} & \begin{tabular}{r|}
12 \\
1 \\
\end{tabular} & 68 & $\begin{array}{r}14 \\
3 \\
\end{array}$ & $\begin{array}{c}25 \\
3 \\
\end{array}$ & 64 & 32 & 99 & $\begin{array}{r}16 \\
3\end{array}$ & 92 & 35 & \begin{tabular}{r|}
23 \\
9
\end{tabular} & 17 & 4 & $\begin{array}{c}195,933 \\
3\end{array}$ \\
\hline $\begin{array}{l}10.252 .67 .15 \\
2\end{array}$ & 61 & 0 & \begin{tabular}{|r|}
78 \\
8
\end{tabular} & $\begin{array}{r}34 \\
8 \\
\end{array}$ & 0 & \begin{tabular}{r|}
12 \\
4 \\
\end{tabular} & 90 & $\begin{array}{r}13 \\
8 \\
\end{array}$ & $\begin{array}{r}21 \\
1\end{array}$ & 78 & $\begin{array}{r}16 \\
2\end{array}$ & 7 & 53 & 32 & 34 & 57 & 34 & 24 & 69 & 23 & \begin{tabular}{r|}
10 \\
9
\end{tabular} & 42 & $\begin{array}{r}11 \\
6\end{array}$ & 50 & 8 & 6 & 5 & 9 & 17 & 5 & $\begin{array}{l}93,3333 \\
3\end{array}$ \\
\hline $\begin{array}{l}10.252 .67 .15 \\
3\end{array}$ & $\begin{array}{r}36 \\
8 \\
\end{array}$ & 0 & \begin{tabular}{r|}
17 \\
7
\end{tabular} & \begin{tabular}{r|}
71 \\
1
\end{tabular} & 0 & \begin{tabular}{r|}
16 \\
9
\end{tabular} & \begin{tabular}{r|}
16 \\
2 \\
\end{tabular} & 47 & \begin{tabular}{r|}
71 \\
3
\end{tabular} & 48 & $\begin{array}{r}67 \\
8\end{array}$ & 45 & $\begin{array}{r}15 \\
7\end{array}$ & \begin{tabular}{r|}
23 \\
5
\end{tabular} & $\begin{array}{r}14 \\
7\end{array}$ & 92 & $\begin{array}{r}17 \\
0\end{array}$ & $\begin{array}{r}28 \\
1 \\
\end{array}$ & 33 & 30 & 15 & $\begin{array}{c}19 \\
3\end{array}$ & $\begin{array}{c}12 \\
3 \\
\end{array}$ & 25 & $\begin{array}{r}27 \\
2\end{array}$ & 7 & 6 & 7 & 9 & 27 & $\begin{array}{c}165,566 \\
7\end{array}$ \\
\hline $\begin{array}{l}10.252 .67 .15 \\
4\end{array}$ & $\begin{array}{r}44 \\
1\end{array}$ & $\begin{array}{r}69 \\
2 \\
\end{array}$ & 31 & \begin{tabular}{r|}
66 \\
4
\end{tabular} & \begin{tabular}{r|r}
91 & \\
0 &
\end{tabular} & $\begin{array}{r}87 \\
4 \\
\end{array}$ & $\begin{array}{r}73 \\
3 \\
\end{array}$ & $\begin{array}{r}46 \\
0\end{array}$ & $\begin{array}{r}27 \\
6 \\
\end{array}$ & $\begin{array}{r}96 \\
9\end{array}$ & 16 & \begin{tabular}{r|}
12 \\
2
\end{tabular} & 81 & \begin{tabular}{r|}
12 \\
4
\end{tabular} & 39 & $\begin{array}{r}15 \\
7\end{array}$ & $\begin{array}{r}40 \\
6\end{array}$ & \begin{tabular}{r|}
12 \\
0
\end{tabular} & $\begin{array}{r}36 \\
4 \\
\end{array}$ & 9 & $\begin{array}{r}12 \\
3 \\
\end{array}$ & $\begin{array}{c}10 \\
3\end{array}$ & $\begin{array}{r}27 \\
1\end{array}$ & $\begin{array}{r}10 \\
4 \\
\end{array}$ & $\begin{array}{r}16 \\
6 \\
\end{array}$ & $\begin{array}{r}23 \\
0\end{array}$ & 38 & $\begin{array}{r}21 \\
5\end{array}$ & 0 & 8 & 292.2 \\
\hline $3^{10.252 .67 .15}$ & $\begin{array}{r}37 \\
9\end{array}$ & $\begin{array}{r}39 \\
1\end{array}$ & $\begin{array}{r}63 \\
2 \\
\end{array}$ & $\begin{array}{r}66 \\
9\end{array}$ & \begin{tabular}{r|}
21 \\
6
\end{tabular} & $\begin{array}{r}47 \\
9\end{array}$ & 87 & \begin{tabular}{r|}
13 \\
7
\end{tabular} & $\begin{array}{r}13 \\
0\end{array}$ & $\begin{array}{r}10 \\
1\end{array}$ & 25 & 29 & \begin{tabular}{r|}
19 \\
9
\end{tabular} & $\begin{array}{r}68 \\
1\end{array}$ & 32 & 37 & 47 & 74 & 14 & $\begin{array}{r}12 \\
0\end{array}$ & $\begin{array}{r}49 \\
0\end{array}$ & 99 & 44 & 54 & 68 & 26 & $\begin{array}{r}22 \\
4 \\
\end{array}$ & 37 & 5 & 6 & $\begin{array}{c}186,066 \\
7\end{array}$ \\
\hline $\begin{array}{l}10.252 .67 .15 \\
6\end{array}$ & $\begin{array}{r}89 \\
9 \\
\end{array}$ & $\begin{array}{r}87 \\
8 \\
\end{array}$ & $\begin{array}{r}79 \\
7\end{array}$ & $\begin{array}{r}44 \\
5\end{array}$ & $\begin{array}{r}26 \\
1\end{array}$ & $\begin{array}{r}99 \\
7 \\
\end{array}$ & 21 & \begin{tabular}{r|}
12 \\
1
\end{tabular} & 45 & $\begin{array}{c}12 \\
3 \\
\end{array}$ & 35 & $\begin{array}{r}16 \\
4\end{array}$ & $\begin{array}{r}41 \\
8 \\
\end{array}$ & $\begin{array}{r}15 \\
1 \\
\end{array}$ & $\begin{array}{r}37 \\
6 \\
\end{array}$ & 21 & 14 & $\begin{array}{r}11 \\
7\end{array}$ & $\begin{array}{r}19 \\
0\end{array}$ & \begin{tabular}{r|}
11 \\
9
\end{tabular} & 37 & $\begin{array}{r}24 \\
2\end{array}$ & 54 & $\begin{array}{r}23 \\
4 \\
\end{array}$ & 63 & 36 & $s 8$ & 74 & 75 & 7 & 237,4 \\
\hline $\begin{array}{l}10.252 .67 .15 \\
7\end{array}$ & $\begin{array}{r}35 \\
3\end{array}$ & $\begin{array}{r}47 \\
2 \\
\end{array}$ & $\begin{array}{r}48 \\
4 \\
\end{array}$ & $\begin{array}{r}67 \\
8\end{array}$ & $\begin{array}{r}55 \\
3\end{array}$ & $\begin{array}{r}28 \\
5 \\
\end{array}$ & $\begin{array}{r}57 \\
7 \\
\end{array}$ & $\begin{array}{r}10 \\
2\end{array}$ & 0 & \begin{tabular}{r|}
22 \\
2
\end{tabular} & $n 7$ & \begin{tabular}{r|}
16 \\
9
\end{tabular} & 11 & 59 & 40 & 83 & 67 & 95 & 37 & 60 & 35 & \begin{tabular}{r|}
11 \\
9
\end{tabular} & 54 & $\begin{array}{r}13 \\
0\end{array}$ & 42 & 7 & 12 & 6 & 5 & 5 & $\frac{167,966}{7}$ \\
\hline $\begin{array}{l}10.252 .67 .15 \\
8\end{array}$ & $\begin{array}{r}74 \\
7\end{array}$ & $\begin{array}{r}98 \\
7 \\
\end{array}$ & \begin{tabular}{r|}
86 \\
4
\end{tabular} & $\begin{array}{r}76 \\
8\end{array}$ & $\begin{array}{r}54 \\
2 \\
\end{array}$ & $\begin{array}{r}35 \\
9 \\
\end{array}$ & $\begin{array}{r}98 \\
6\end{array}$ & 98 & 99 & 18 & 83 & \begin{tabular}{|r|}
13 \\
8
\end{tabular} & \begin{tabular}{r|}
10 \\
1
\end{tabular} & \begin{tabular}{r|}
53 \\
1 \\
\end{tabular} & 37 & \begin{tabular}{r|}
48 \\
6
\end{tabular} & 52 & 33 & 26 & \begin{tabular}{c|}
11 \\
5 \\
\end{tabular} & \begin{tabular}{r|}
19 \\
6 \\
\end{tabular} & 30 & 69 & \begin{tabular}{r|}
16 \\
3
\end{tabular} & $\begin{array}{r}34 \\
2\end{array}$ & $\begin{array}{r}17 \\
1\end{array}$ & 34 & 33 & 67 & 56 & $\begin{array}{l}279,033 \\
3\end{array}$ \\
\hline $\begin{array}{l}10.252 .67 .15 \\
9\end{array}$ & $\begin{array}{r}98 \\
2 \\
\end{array}$ & $\begin{array}{r}45 \\
2 \\
\end{array}$ & $\begin{array}{r}47 \\
5\end{array}$ & $\begin{array}{r}48 \\
7\end{array}$ & $\begin{array}{r}65 \\
0\end{array}$ & \begin{tabular}{r|}
38 \\
9 \\
\end{tabular} & $\begin{array}{r}27 \\
4 \\
\end{array}$ & \begin{tabular}{r|}
58 \\
0
\end{tabular} & \begin{tabular}{r|}
10 \\
5
\end{tabular} & 0 & $\begin{array}{r}22 \\
3\end{array}$ & 78 & \begin{tabular}{r|}
16 \\
9
\end{tabular} & 11 & 99 & 41 & 94 & 62 & 94 & 35 & 87 & 32 & \begin{tabular}{r|}
11 \\
6
\end{tabular} & 50 & $\begin{array}{r}12 \\
2 \\
\end{array}$ & 60 & 6 & 5 & 7 & 4 & $\begin{array}{c}191,633 \\
3\end{array}$ \\
\hline $\begin{array}{l}0^{10.252 .67 .16} \\
\end{array}$ & $\begin{array}{r}83 \\
5\end{array}$ & $\begin{array}{r}92 \\
5\end{array}$ & $\begin{array}{r}37 \\
0\end{array}$ & \begin{tabular}{|c|}
18 \\
5
\end{tabular} & $\begin{array}{r}91 \\
6\end{array}$ & $\begin{array}{r}44 \\
2 \\
\end{array}$ & 37 & 47 & 40 & $\begin{array}{r}22 \\
4\end{array}$ & 81 & $\begin{array}{r}33 \\
2 \\
\end{array}$ & 62 & $\begin{array}{r}28 \\
5\end{array}$ & 7 & 44 & 23 & \begin{tabular}{r|}
18 \\
7
\end{tabular} & 34 & 82 & $\begin{array}{r}14 \\
5\end{array}$ & 45 & $\begin{array}{r}14 \\
6\end{array}$ & 14 & \begin{tabular}{|c|}
13 \\
5
\end{tabular} & 61 & 20 & 22 & 9 & 50 & 193,5 \\
\hline $\begin{array}{l}10.252 .67 .16 \\
1\end{array}$ & \begin{tabular}{r|}
33 \\
5
\end{tabular} & $\begin{array}{r}87 \\
1\end{array}$ & \begin{tabular}{l|}
69 \\
0
\end{tabular} & \begin{tabular}{r|}
16 \\
0
\end{tabular} & $\begin{array}{r}42 \\
4 \\
\end{array}$ & 32 & 78 & 71 & 42 & 22 & \begin{tabular}{r|}
45 \\
7
\end{tabular} & \begin{tabular}{|c|}
13 \\
3
\end{tabular} & \begin{tabular}{r|}
78 \\
3
\end{tabular} & 37 & 21 & 75 & 17 & 37 & 0 & $n$ & \begin{tabular}{r|}
11 \\
6
\end{tabular} & 42 & 67 & 36 & 9 & 46 & 6 & 5 & 6 & 5 & $\begin{array}{c}156,665 \\
7\end{array}$ \\
\hline $\begin{array}{l}10.252 .67 .16 \\
2\end{array}$ & $\begin{array}{r}11 \\
7\end{array}$ & $\begin{array}{r}19 \\
4 \\
\end{array}$ & $\begin{array}{r}10 \\
5\end{array}$ & $s 1$ & $\begin{array}{r}12 \\
6 \\
\end{array}$ & $\begin{array}{r}23 \\
5\end{array}$ & 46 & $\begin{array}{r}18 \\
1 \\
\end{array}$ & 34 & $\begin{array}{r}14 \\
9\end{array}$ & $n$ & 26 & $\begin{array}{c}22 \\
5\end{array}$ & 7 & 8 & 8 & 8 & 5 & 15 & $\begin{array}{r}55 \\
5\end{array}$ & 7 & 8 & 21 & 5 & 11 & 9 & 7 & 6 & 5 & 10 & $\begin{array}{c}77,0333 \\
3\end{array}$ \\
\hline $\begin{array}{l}10.252 .67 .16 \\
3\end{array}$ & $\begin{array}{r}37 \\
0\end{array}$ & $\begin{array}{r}18 \\
6 \\
\end{array}$ & $\begin{array}{r}92 \\
0\end{array}$ & $\begin{array}{r}44 \\
7 \\
\end{array}$ & 42 & 48 & 44 & $\begin{array}{l}22 \\
9\end{array}$ & 92 & $\begin{array}{r}34 \\
4 \\
\end{array}$ & 75 & $\begin{array}{r}29 \\
9\end{array}$ & 11 & 57 & 36 & $\begin{array}{r}20 \\
2\end{array}$ & 50 & 98 & $\begin{array}{r}16 \\
1 \\
\end{array}$ & 41 & $\begin{array}{r}16 \\
0\end{array}$ & 29 & \begin{tabular}{r|}
15 \\
0
\end{tabular} & 71 & 22 & 16 & 10 & 6 & 9 & 8 & 141,1 \\
\hline $\begin{array}{l}10.252 .67 .16 \\
4\end{array}$ & $\begin{array}{r}64 \\
2\end{array}$ & \begin{tabular}{r|}
11 \\
2
\end{tabular} & $\begin{array}{r}37 \\
3 \\
\end{array}$ & $\begin{array}{r}10 \\
4\end{array}$ & 33 & 23 & $\begin{array}{r}24 \\
9\end{array}$ & 30 & $\begin{array}{r}80 \\
0\end{array}$ & 90 & $\begin{array}{r}76 \\
7\end{array}$ & 15 & 54 & 25 & 70 & 61 & 39 & $\begin{array}{r}37 \\
8\end{array}$ & 71 & 36 & 38 & $\begin{array}{r}29 \\
2\end{array}$ & $\begin{array}{r}22 \\
6\end{array}$ & $\begin{array}{r}12 \\
0\end{array}$ & $\begin{array}{r}25 \\
5\end{array}$ & 10 & 6 & 9 & 22 & 0 & 165 \\
\hline $\begin{array}{l}10.252 .67 .16 \\
5\end{array}$ & $\begin{array}{r}27 \\
3\end{array}$ & $\begin{array}{r}39 \\
6 \\
\end{array}$ & 71 & 91 & 57 & $\begin{array}{r}16 \\
1\end{array}$ & $\begin{array}{r}18 \\
0\end{array}$ & 35 & $\begin{array}{r}13 \\
0\end{array}$ & 16 & 20 & 24 & 33 & 24 & 50 & \begin{tabular}{r|}
15 \\
8
\end{tabular} & 49 & 0 & 41 & 3 & 49 & 5 & 7 & 8 & 7 & $\begin{array}{r}17 \\
0\end{array}$ & 8 & 5 & 11 & 7 & $\begin{array}{c}72,0333 \\
3\end{array}$ \\
\hline $\begin{array}{l}10.252 .67 .16 \\
6\end{array}$ & $\begin{array}{c}22 \\
5\end{array}$ & $\begin{array}{r}22 \\
6 \\
\end{array}$ & 27 & 94 & 85 & $\begin{array}{r}20 \\
5\end{array}$ & $\begin{array}{r}63 \\
6 \\
\end{array}$ & $\begin{array}{r}14 \\
4 \\
\end{array}$ & $\begin{array}{r}59 \\
7\end{array}$ & 18 & 61 & $\begin{array}{r}13 \\
7\end{array}$ & 45 & $\begin{array}{r}22 \\
4 \\
\end{array}$ & 65 & $\begin{array}{r}17 \\
2 \\
\end{array}$ & $\begin{array}{r}26 \\
6\end{array}$ & $\begin{array}{r}11 \\
8\end{array}$ & 26 & 82 & 74 & 22 & $\begin{array}{r}16 \\
8\end{array}$ & 5 & 10 & 7 & 22 & 8 & 9 & $\begin{array}{r}49 \\
1\end{array}$ & $\begin{array}{c}143,666 \\
7\end{array}$ \\
\hline $\begin{array}{l}10.252 .67 .16 \\
7\end{array}$ & $\begin{array}{r}71 \\
8\end{array}$ & $\begin{array}{r}24 \\
3 \\
\end{array}$ & $\begin{array}{r}37 \\
8\end{array}$ & 49 & 59 & 24 & $\begin{array}{r}13 \\
1 \\
\end{array}$ & $\begin{array}{r}14 \\
8\end{array}$ & 30 & 94 & 7 & \begin{tabular}{r|}
21 \\
9
\end{tabular} & $\begin{array}{r}15 \\
1 \\
\end{array}$ & 20 & \begin{tabular}{r|}
28 \\
5
\end{tabular} & 18 & $\begin{array}{r}12 \\
5 \\
\end{array}$ & 15 & $\begin{array}{r}13 \\
4 \\
\end{array}$ & 53 & \begin{tabular}{r|}
18 \\
1
\end{tabular} & 60 & $\begin{array}{r}19 \\
5 \\
\end{array}$ & 0 & 8 & 6 & $\begin{array}{r}18 \\
5 \\
\end{array}$ & 7 & 5 & 21 & $\begin{array}{c}119,633 \\
3\end{array}$ \\
\hline $\begin{array}{l}10.252 .67 .16 \\
8\end{array}$ & $\begin{array}{r}58 \\
6 \\
\end{array}$ & $\begin{array}{r}24 \\
0\end{array}$ & $\begin{array}{r}24 \\
1\end{array}$ & 44 & $\begin{array}{r}11 \\
3 \\
\end{array}$ & $\begin{array}{r}10 \\
4\end{array}$ & $\begin{array}{r}22 \\
3\end{array}$ & $\begin{array}{r}63 \\
8 \\
\end{array}$ & $\begin{array}{r}11 \\
9\end{array}$ & $\begin{array}{r}60 \\
0\end{array}$ & 14 & 70 & $\begin{array}{r}14 \\
6\end{array}$ & 37 & $\begin{array}{r}12 \\
1 \\
\end{array}$ & 77 & \begin{tabular}{r|}
18 \\
5
\end{tabular} & $\begin{array}{r}15 \\
8\end{array}$ & \begin{tabular}{r|}
23 \\
9
\end{tabular} & 32 & 94 & 21 & 26 & $\begin{array}{r}16 \\
7\end{array}$ & 7 & 10 & 5 & 19 & 5 & 12 & $\begin{array}{c}145,766 \\
7\end{array}$ \\
\hline $\begin{array}{l}10.252 .67 .16 \\
9\end{array}$ & 84 & $\begin{array}{r}82 \\
3\end{array}$ & $\begin{array}{r}34 \\
9\end{array}$ & $\begin{array}{r}39 \\
4\end{array}$ & 33 & $\begin{array}{r}16 \\
6 \\
\end{array}$ & $\begin{array}{r}13 \\
3 \\
\end{array}$ & 27 & $\begin{array}{r}25 \\
9\end{array}$ & \begin{tabular}{r|}
11 \\
9
\end{tabular} & \begin{tabular}{r|}
21 \\
21
\end{tabular} & 23 & $\begin{array}{r}10 \\
4 \\
\end{array}$ & 59 & \begin{tabular}{r|}
12 \\
5
\end{tabular} & 43 & 18 & 81 & 67 & 83 & so & 72 & so & 72 & 8 & 8 & 4 & 22 & 4 & 6 & $\begin{array}{c}116,666 \\
7\end{array}$ \\
\hline $\begin{array}{l}10.252 .67 .17 \\
0^{2}\end{array}$ & $\begin{array}{r}22 \\
5\end{array}$ & 27 & 94 & 82 & $\begin{array}{r}20 \\
0\end{array}$ & $\begin{array}{r}62 \\
9 \\
\end{array}$ & $\begin{array}{r}13 \\
7\end{array}$ & $\begin{array}{r}58 \\
8 \\
\end{array}$ & 48 & 51 & $\begin{array}{r}12 \\
8\end{array}$ & 38 & $\begin{array}{r}21 \\
6 \\
\end{array}$ & 56 & \begin{tabular}{r|}
16 \\
1
\end{tabular} & $\begin{array}{r}25 \\
3\end{array}$ & $\begin{array}{r}43 \\
6 \\
\end{array}$ & 15 & 38 & 53 & 34 & $\begin{array}{r}14 \\
7\end{array}$ & 27 & 9 & 6 & 11 & 5 & 10 & $\begin{array}{r}46 \\
8\end{array}$ & 6 & 140,6 \\
\hline $\begin{array}{l}10.252 .67 .17 \\
1\end{array}$ & $\begin{array}{r}34 \\
7 \\
\end{array}$ & 16 & 26 & 30 & $\begin{array}{r}10 \\
4 \\
\end{array}$ & \begin{tabular}{r|}
12 \\
0
\end{tabular} & 24 & 32 & 8 & $\begin{array}{r}20 \\
6\end{array}$ & \begin{tabular}{r|}
15 \\
2
\end{tabular} & $\begin{array}{r}16 \\
7 \\
\end{array}$ & $\begin{array}{r}28 \\
5\end{array}$ & \begin{tabular}{r|}
15 \\
5 \\
\end{tabular} & $\begin{array}{r}11 \\
7\end{array}$ & 34 & $\begin{array}{r}12 \\
6 \\
\end{array}$ & 44 & \begin{tabular}{r|}
18 \\
5
\end{tabular} & 50 & $\begin{array}{r}24 \\
7\end{array}$ & 9 & 7 & 8 & 12 & 6 & 6 & 9 & \begin{tabular}{r|}
17 \\
8
\end{tabular} & 6 & 92,2 \\
\hline $\begin{array}{l}10.252 .67 .17 \\
2\end{array}$ & 26 & 49 & 39 & \begin{tabular}{c|}
15 \\
9
\end{tabular} & $\begin{array}{r}59 \\
0\end{array}$ & 97 & $\begin{array}{r}54 \\
7\end{array}$ & 35 & 10 & 85 & 54 & $\begin{array}{r}17 \\
4 \\
\end{array}$ & 14 & \begin{tabular}{r|}
11 \\
9 \\
\end{tabular} & \begin{tabular}{r|}
21 \\
4
\end{tabular} & $\begin{array}{r}39 \\
4\end{array}$ & 44 & 14 & 27 & 31 & 98 & 9 & 7 & 10 & 9 & 20 & 8 & $\begin{array}{r}41 \\
9\end{array}$ & 8 & 4 & $\underset{3}{111,133}$ \\
\hline 10.25267 .17 & $\begin{array}{r}22 \\
1\end{array}$ & 34 & 11 & 63 & 10 & 36 & 13 & \begin{tabular}{c|}
11 \\
8
\end{tabular} & \begin{tabular}{r|}
12 \\
9
\end{tabular} & 97 & 96 & \begin{tabular}{r|}
20 \\
5
\end{tabular} & 74 & 36 & 37 & 45 & 34 & $\begin{array}{ll}11 \\
0\end{array}$ & \begin{tabular}{r|}
14 \\
2
\end{tabular} & $\begin{array}{r}17 \\
7 \\
\end{array}$ & 7 & 33 & 22 & 5 & 7 & 4 & 6 & $\begin{array}{r}12 \\
2 \\
\end{array}$ & 6 & 6 & $\begin{array}{c}66.8666 \\
7\end{array}$ \\
\hline $\begin{array}{l}10.252 .67 .17 \\
4\end{array}$ & 41 & 96 & $s 8$ & $\begin{array}{r}48 \\
7\end{array}$ & 61 & $\begin{array}{r}44 \\
0\end{array}$ & 16 & 36 & \begin{tabular}{c|}
18 \\
5
\end{tabular} & 73 & $\begin{array}{c}15 \\
5\end{array}$ & 81 & 26 & \begin{tabular}{r|}
11 \\
6
\end{tabular} & $\begin{array}{r}29 \\
3 \\
\end{array}$ & \begin{tabular}{c|}
12 \\
3 \\
\end{tabular} & 97 & 70 & 34 & 48 & 6 & 5 & 15 & 6 & 26 & 66 & \begin{tabular}{r|}
34 \\
7
\end{tabular} & 6 & 7 & 7 & 100.9 \\
\hline $\begin{array}{l}10.252 .67 .17 \\
5\end{array}$ & $\begin{array}{r}75 \\
9\end{array}$ & 46 & $\begin{array}{r}72 \\
3\end{array}$ & 44 & 9 & $\begin{array}{r}28 \\
4 \\
\end{array}$ & 25 & 54 & $\begin{array}{r}20 \\
0\end{array}$ & $\begin{array}{r}33 \\
2 \\
\end{array}$ & 25 & 46 & 43 & $\begin{array}{r}24 \\
8\end{array}$ & \begin{tabular}{r|}
17 \\
6
\end{tabular} & s1 & $\begin{array}{r}26 \\
8 \\
\end{array}$ & 12 & 10 & 9 & $s$ & 22 & 9 & 39 & 12 & 23 & 21 & 7 & 17 & 9 & 118,7 \\
\hline $\begin{array}{l}10.252 .67 .17 \\
6\end{array}$ & 22 & $\begin{array}{r}27 \\
2\end{array}$ & 57 & 0 & 39 & $\begin{array}{r}20 \\
5\end{array}$ & $\begin{array}{r}31 \\
8 \\
\end{array}$ & 33 & 61 & 21 & \begin{tabular}{r|}
22 \\
4
\end{tabular} & \begin{tabular}{|l|}
15 \\
2
\end{tabular} & 56 & $\begin{array}{r}30 \\
1 \\
\end{array}$ & 5 & 12 & 4 & 8 & 7 & 6 & 20 & 3 & $s$ & 8 & 9 & 0 & 10 & 9 & 26 & 65 & $\begin{array}{c}65,4333 \\
3\end{array}$ \\
\hline $\begin{array}{l}10.252 .67 .17 \\
7\end{array}$ & 49 & $\begin{array}{r}26 \\
8\end{array}$ & $\begin{array}{r}17 \\
0\end{array}$ & $\begin{array}{r}65 \\
5\end{array}$ & 26 & 61 & 17 & ss & 40 & 93 & $\begin{array}{r}46 \\
4 \\
\end{array}$ & 71 & 32 & 27 & 40 & \begin{tabular}{r|}
31 \\
2
\end{tabular} & $\begin{array}{r}20 \\
0\end{array}$ & 86 & 6 & 9 & 13 & 7 & 6 & 5 & 6 & 5 & 28 & 3 & 6 & 11 & $\begin{array}{c}92,4333 \\
3\end{array}$ \\
\hline $\begin{array}{l}10.252 .67 .17 \\
8\end{array}$ & 18 & $\begin{array}{r}14 \\
6\end{array}$ & $\begin{array}{r}39 \\
1\end{array}$ & $\begin{array}{c}11 \\
9\end{array}$ & $\begin{array}{l}34 \\
3\end{array}$ & 6 & $\begin{array}{r}10 \\
6\end{array}$ & 57 & \begin{tabular}{r|}
16 \\
2
\end{tabular} & 0 & 34 & $\begin{array}{c}23 \\
8\end{array}$ & $\begin{aligned} 16 \\
6\end{aligned}$ & 71 & \begin{tabular}{r|}
30 \\
1
\end{tabular} & 7 & 10 & 14 & 11 & 14 & 9 & 37 & 3 & 21 & 7 & 9 & 3 & 6 & 23 & 7 & 79.2 \\
\hline $9_{9}^{10.252 .67 .17}$ & $5 s$ & 68 & 35 & $\begin{array}{c}25 \\
3 \\
\end{array}$ & $\begin{array}{r}17 \\
6 \\
\end{array}$ & 54 & $\begin{array}{r}10 \\
1\end{array}$ & \begin{tabular}{r|}
11 \\
2
\end{tabular} & 78 & 76 & $\begin{array}{r}18 \\
5\end{array}$ & 53 & 14 & 18 & 24 & 62 & 87 & $\begin{array}{r}28 \\
7\end{array}$ & $\begin{array}{r}15 \\
2\end{array}$ & 17 & 14 & 8 & 40 & 8 & 4 & 5 & 95 & 5 & 6 & 12 & $\begin{array}{c}70,1333 \\
3\end{array}$ \\
\hline
\end{tabular}

Gambar 12. Pengujian setelah topologi diterapkan dengan beban pengetesan 
Berdasarkan dari hasil pengujian di atas dapat dirangkum ke dalam Tabel 1 di bawah ini:

Tabel 1. Kesimpulan pengujian

\begin{tabular}{cccc}
\hline \multicolumn{2}{c}{ Sebelum Topologi diterapkan } & \multicolumn{2}{c}{ Setelah Topologi diterapkan } \\
\hline $\begin{array}{c}\text { Ping rata-rata tanpa beban } \\
(30 \mathrm{pc})\end{array}$ & $11,08 \mathrm{~ms}$ & $\begin{array}{c}\text { Ping rata-rata tanpa beban } \\
(30 \mathrm{pc})\end{array}$ & $14,95 \mathrm{~ms}$ \\
\hline $\begin{array}{c}\text { Ping rata- rata dengan beban } \\
(30 \mathrm{pc})\end{array}$ & $392,98 \mathrm{~ms}$ & $\begin{array}{c}\text { Ping rata-rata dengan } \\
\text { beban }(30 \mathrm{pc})\end{array}$ & $143,50 \mathrm{~ms}$ \\
\hline
\end{tabular}

\section{KESIMPULAN DAN SARAN}

Berdasarkan hasil pengujian yang telah dilakukan dalam penelitian ini, maka dapat diambil simpulan bahwa, 30 user aktif menjalankan aplikasi EDMS, disimpulkan bahwa rata-rata ping sebelum menjalankan topologi diterapkan mendapatkan hasil sebesar $11,08 \mathrm{~ms}$ dan setelah topologi diterapkan mendapatkan hasil sebesar 14,95 ms. Maka disimpulkan jaringan setelah topologi diterapkan tidak jauh berbeda dengan jaringan sebelumnya.

Tiga puluh user aktif menjalankan aplikasi EDMS dan melakukan upload file dengan ukuran yang sama secara bersamaan, disimpulkan bahwa hasil rata-rata ping sebelum topologi diterapkan mendapatkan hasil sebesar 392,98 $\mathrm{ms}$ dan setelah topologi mendapatkan hasil yang lebih baik saat melakukan aktifitas dalam menjalankan aplikasi EDMS dibandingkan dengan jaringan sebelumnya.

Saran dari hasil penelitian ini adalah pemasangan server pada sisi kantor proyek sehingga dapat menyimpan berkas-berkas terlebih dahulu sebelum diakses oleh pengguna secara lokal tanpa terhubung melalui media internet.

\section{DAFTAR PUSTAKA}

[1] Onswar, Z.L. 2016, Analisis Simulasi Topologi Hybrid Pada Wireless Sensor Network Menggunakan Protokol Routing Optimized Link State Routing Dan Dynamic Source Routing, ISSN: 2355-9365, Vol.3. No.3. hal.4477-4488.

[2] Ismail, N. 2017, Analisis Perbadingan Kinerja Topologi Mesh dan Hybrid Pada Jaringan Optik WDM Dengan Menggunakan Algoritma First-Fit,
ISSN: 1979-8911, Vol.10. No.1. hal.5267.

[3] Novriyanto, S.T., M.Sc.2011, Sistem Pendeteksian Penyusup Jaringan Komputer Dengan Active Response Menggunakan Metode Hybrid Intrusion Detection, Signatures dan Anomaly Detection, ISSN: 1907-5022, hal.F-140F-145.

[4] Sukmaaji, A, Rianto. 2008, Jaringan Komputer, Andi, Yogyakarta.

[5] Sofana, I. 2008, CISCO CCNA \& Jaringan Komputer, Informatika Bandung.

[6] Handriyanto, Dwi Febrian. 2009, Kajian Menggunakan Mikrotik Router OS Sebagai Router Pada Jaringan Komputer, Universitas Sriwijaya, Sumatera Selatan.

[7] Forouzan, B. A 2007, Data Communications and Networking, 4rd edition, McGraw-Hill.

[8] EMDS. EDMS Electronic Document Management System. http://www.edms.net/. Diakses tanggal 4 Oktober 2017. 